\title{
The Rete Mirabile of the Maxillary Artery in the Cat
}

\author{
By \\ Akimichi TAKemURA \\ Department of Anatomy, Osaka Dental University, \\ 1-47 Kyobashi, Higashi-ku, Osaka 540, Japan \\ (Director: Prof. Y. Ohta) \\ (with eight textfigures and twenty-three figures in four plates) \\ -Received for Publication; March 18, 1982-
}

Key words: Maxillary artery, Rete mirabile, Plastic injection, Comparative anatomy, Cat.

Summary: The rete mirabile of the maxillary artery was studied in the cat by means of the acryl plastic injection method. Four afferent arterial vessels of the rete were investigated as follows: the lateral retial branches arising from the posterior deep temporal and the inferior alveolar arteries outside the rete, the medial retial branches arising from the middle meningeal and the maxillary arteries, the anterior retial branches arising from the buccal, the anterior deep temporal and the zygomatic arteries, and the intraretial branches arising from the maxillary artery within the rete. The lateral retial branch was similar in its course to the maxillary artery in the crab-eating monkey and man. An arterial circle was formed by the lateral retial branch, the maxillary artery and the posterior part of the rete, and contained the lateral pterygoid muscle and the mandibular nerve. In the formation of the rete, its deep portion around the maxillary artery and nerve was formed by the intraretial branches, its superficial portion by the other afferent vessels, and the intermediate portion by rich anastomoses between both portions. Eight efferent arterial vessels were observed as follows: the external ethmoidal, the meningeal, the extraocular muscular, the lacrimal, a communicating branch with the external ethmoidal, the temporal branch, the interretial artery (which was proper in the cat) and the anastomotic artery (rr. retis of Nomina anatomica veterinaria 1973) which was formed by a confluence of the component branches of the rete. The anastomotic artery played a significant role in the blood supply to the brain, after receiving the anastomotic ramus originating from the middle meningeal artery instead of the degenerated and obturated remnant of the internal carotid artery.

The rete mirabile of the maxillary artery was first described by Tandler (1899). Subsequently, angiological studies of the rete were undertaken by Hürlimann (1913). Davis et al. (1943) made a detailed survey of the efferent vessels of the rete in accurate illustrations but without the afferent vessels. Daniel et al. (1953) at- tempted an analysis by comparing the rete in the cat with that seen in some other mammals. Martínez (1967) stated that the rete was formed by three kinds of afferent vessels. However, he presented a simplified description of the origin and courses of the afferent vessels and relations with surrounding structures and 
efferent vessels. Although the rete, being proper in the cat, is located in the external carotid system, it is an important bloodresource to the brain while the orbital contents are also supplied. The strong anastomotic artery, which is formed by confluence of the component branches of the rete, supplies a majority of the blood to the brain, instead of the degenerated and obturated internal catotid artery.

Previous studies on the rete have not been consistent in investigating the full features ranging from the afferent vessels to the efferent vessels based on the vascularization of the rete. In this paper, the author will attempt to give a detailed description of the rete mirabile of the cat in individual specimens based on many examples obtained by the acryl plastic injection method. Furthermore, the author will express an opinion on the nomenclature given by previous scholars and in the Nomina anatomica veterinaria.

\section{Materials and Methods}

Fifty-five adult cats and five newborn cats were used. Acryl plastic was injected via their common carotid arteries by means of the plastic injection method (1952, 1955). Forty-five injected heads of the adult cats were treated with sodium hydroxide to obtain corrosion specimens, in order to elucidate the detailed anatomy and dimensions of the afferent and efferent vessels and the vascularization of the rete. Eight injected heads were preserved in formalin solution for dissection. The remaining injected heads were sectioned in the median plane, and fixed in formalin solution, embedded in celloidin to make serial histological slides of $200 \mu \mathrm{m}$ in thickness, which were stained with hematoxylin and eosin, and sectioned in the frontal, horizontal and sagittal planes, respectively. The five nowborn heads were prepared as corrosion specimens of the carotid system in order to study the relations between the rete and the as yet non-obturated internal carotid artery. Five adult dogs were also employed for comparative studies on the carotid system.

\section{Findings}

The maxillary artery ran forwards between the mandibular ramus and the medial pterygoid muscle and bent medially inferoanterior to the insertion of the lateral pterygoid muscle, where the inferior alveolar, the posterior deep temporal arteries and the lateral retial branches diverged separately or in common (Figs. 1, 9, 10, 16). The artery ran medially beneath the mandibular nerve (Figs. 2,4) after crossing beneath the lateral pterygoid muscle and bent anteriorly lateral to the oval foramen, where the middle meningeal artery and the medial retial branches diverged separately or in common (Figs. 4,11 ). It finally continued to run forwards above the origin of the muscle up to the posterior corner (kaudoventrale Ecke of Hürlimann 1913) and entered the rete mirabile along the lateral side of the maxillary nerve in 88 cases of the 90 examples observed, and passed anteriorly and slightly laterally in the inferolateral portion of the rete (Fig. 12). En route it gave rise to the external ophthalmic artery (a. ciliaris of Davis et al. 1943) and the intraretial branches (Figs. 6, 21). In two cases, the maxillary artery was fused in the rete as the medial retial branches, although instead of it a thick, well-developed, lateral retial branch, which also gave rise to the external ophthalmic and the intraretial branches, penetrated the rete (Fig. 13). The maxillary artery gave rise to the buccal artery immediately proximal to the anterior end of the rete and to the anterior deep temporal and the zygomatic arteries (Davis et al.) immediately distal to it, separately or via a common stem. 
The anterior retial branches diverged from this stem, the anterior deep temporal, the zygomatic or the buccal artery (Figs. 1, $10,15)$.

I. Afferent arterial branches to the rete

As afferent branches, there were the lateral retial branches, the medial retial branches and the anterior retial branches, the origins of all of which were located outside the rete, but the intraretial branches arose within it.

1. Afferent branches arising outside the rete

1) Lateral retial branches

These branches $(0.10 \sim 1.30$, M. $0.47 \mathrm{~mm}$ in diameter), numbering $1 \sim 6$ (three in 35 cases, two in 29 cases, four in 14 cases, one in nine cases, five in two cases, and six in one case), arose anteromedially from the anterior or anteromedial wall of the posterior deep tomporal artery $(0.42 \sim 0.70$, M. $0.55 \mathrm{~mm}$ in diameter) (Figs. 1, 9, 10). In 41 cases, one or two lateral retial branches arose anteromedially from the anteromedial wall of the inferior alveolar artery $(0.45 \sim 0.70$, M. $0.59 \mathrm{~mm}$ in diameter) (Fig. 10). The posterior deep temporal artery in 18 cases arose in common with the inferior alveolar artery (Fig. 16). In one case, the component arterial branches of the rete diverged from the origin of the posterior deep temporal arising from the maxillary at the posterior end of the rete. These branches formed part of the rete which was usually composed of the lateral retial branches and the posterior intraretial branches. In this case, a thin, lateral retial branch (ca. $0.20 \mathrm{~mm}$ ) left the posterior deep temporal proximal to the origin of the masseteric artery, and a communicating twig (ca. $0.30 \mathrm{~mm}$ ) was observed between the inferior alveolar and the posterior deep temporal arteries (Fig. 14).

The lateral retial branches showed many variations in their thickness and number.
In 85 of the examples observed, one or two (one in 79 cases, and two in six cases) of the branches were thick $(0.30 \sim 1.30, \mathrm{M}$. $0.62 \mathrm{~mm}$ ). The more they were increased in thickness, the lesser were the other remaining branches so $(0.10 \sim 0.30$, M. 0.18 $\mathrm{mm})$. However, if their number was increased, their thickness did not increase. The thicker branch $(0.30 \sim 0.60$, M. 0.48 $\mathrm{mm})$ in 47 of the 85 cases showed a constriction around its origin. In five of the examples observed, no such thick branch was noted, but thinner branches $(0.10 \sim 0.30$, M. $0.17 \mathrm{~mm}$ ), numbering more than four in four cases and one in one case, were seen.

a) Lateral retial branches arising from the posterior deep temporal artery

These branches $(0.10 \sim 1.30$, M. $0.48 \mathrm{~mm})$ were seen to be one to six in number (two in 45 cases, three in 23 cases, one in 16 cases, four in three cases, five in one case, and six in one case).

The branch in 80 of the examples observed was a thick one only. In 42 of the 80 cases, the branch, similar in thickness $(0.30 \sim 0.60, M .0 .48 \mathrm{~mm})$ to the posterior deep temporal, arose $1 \sim 2 \mathrm{~mm}$ dorsal to its origin. In the remaining 38 cases, the branch was so thick $(0.60 \sim 1.30$, M. 0.93 $\mathrm{mm})$, i.e. thicker than the parent artery, that it was represented as a direct branch of the maxillary artery. The posterior deep temporal, as a branch of this strong lateral retial branch, arose $0.5 \sim 1.5 \mathrm{~mm}$ distal to its origin (Fig. 15). Furthermore, this branch in eight of the 38 cases, in which it diverged from a thick common stem between the posterior deep temporal and the inferior alveolar, showed such notable features as both arteries arose from this strong lateral retial branch. In two of the eight cases, the lateral retial branch was well-developed (ca. $1.30 \mathrm{~mm}$ ), but the maxillary artery was thinner (ca. $0.65 \mathrm{~mm}$ ), terminating as the medial retial branch, and the lateral retial branch itself 


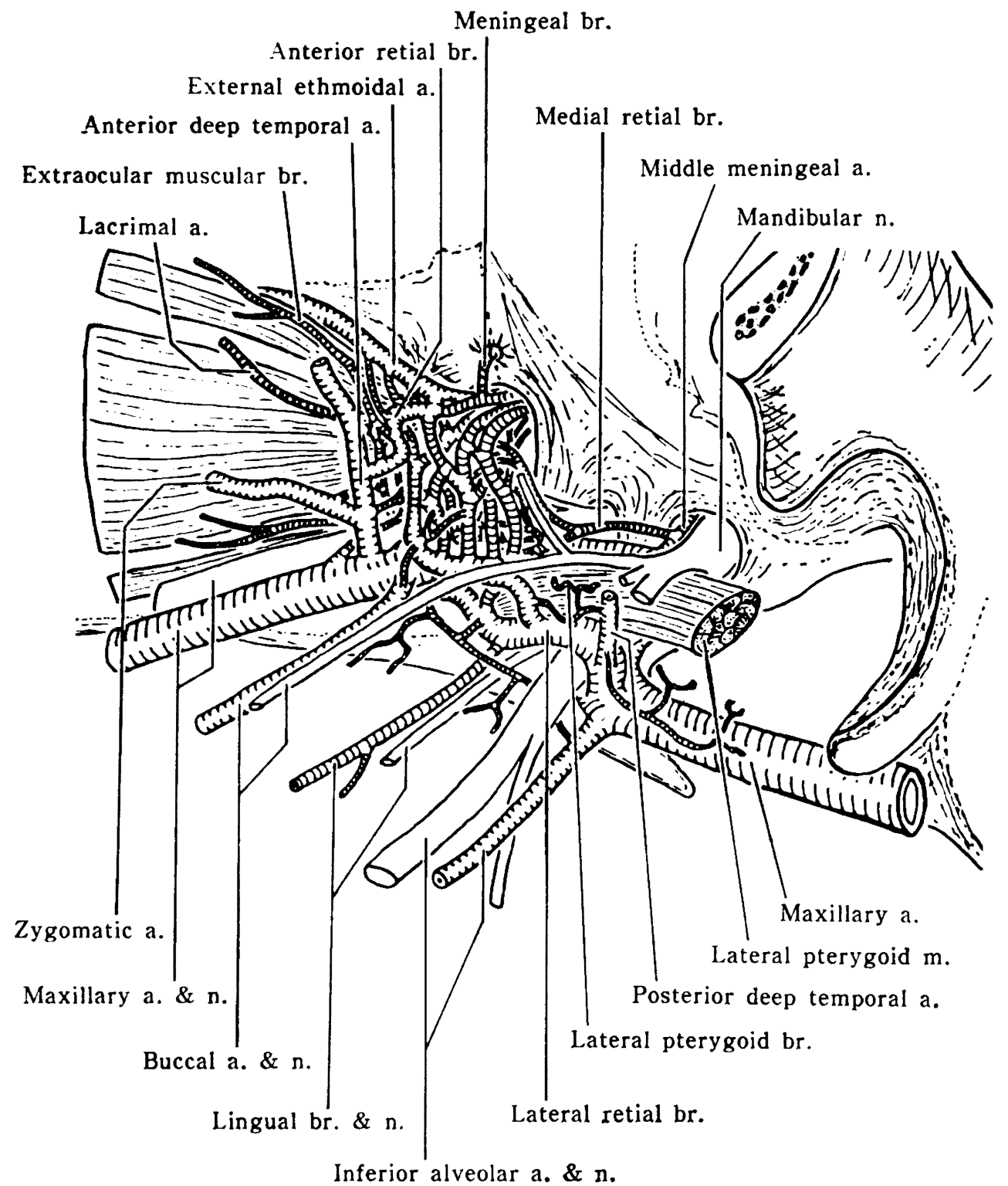

Fig. 1. Lateral view of the left side. Schematic illustration of the rete mirabile and its vicinity. The mandible and the zygomatic arch were removed. The rete of the maxillary artery ranges from the oval foramen to the optic canal, surrounding the maxillary artery and nerve. In this drawing, a thick, lateral retial branch can be seen to pass above the mandibular nerve, and lateral to the pterygoid muscle.

penetrated the rete instead of the maxillary. That is to say, the inferior alveolar left the strong lateral retial branch anteroinferolaterally, the posterior deep temporal superiorly and the medial retial branch, supposedly the maxillary artery, medially
(Fig. 13).

In nine cases among the examples observed, such a thick lateral retial branch was not observed, but numerous fine branches were seen. However, a thick branch in five cases arose from the in- 
ferior alveolar artery. In the one remaining case, the posterior deep temporal arose from the maxillary artery at the posterior end of the rete (Fig. 14).

b) Lateral letial branches arising from the inferior alveolar artery

This branch $(0.10 \sim 0.80$, M. $0.41 \mathrm{~mm}$ in diameter) numbered one or two (one in 37 cases and two in four cases). In the 41 cases mentioned, in addition to that arising from the posterior deep temporal, this branch arose from the inferior alveolar (Fig. 10). In 30 of the 41 cases, the branch was fine $(0.10 \sim 0.30, \mathrm{M} .0 .16 \mathrm{~mm})$. In 29 of these 30 case, a fine branch was seen in addition to a thick one from the post-

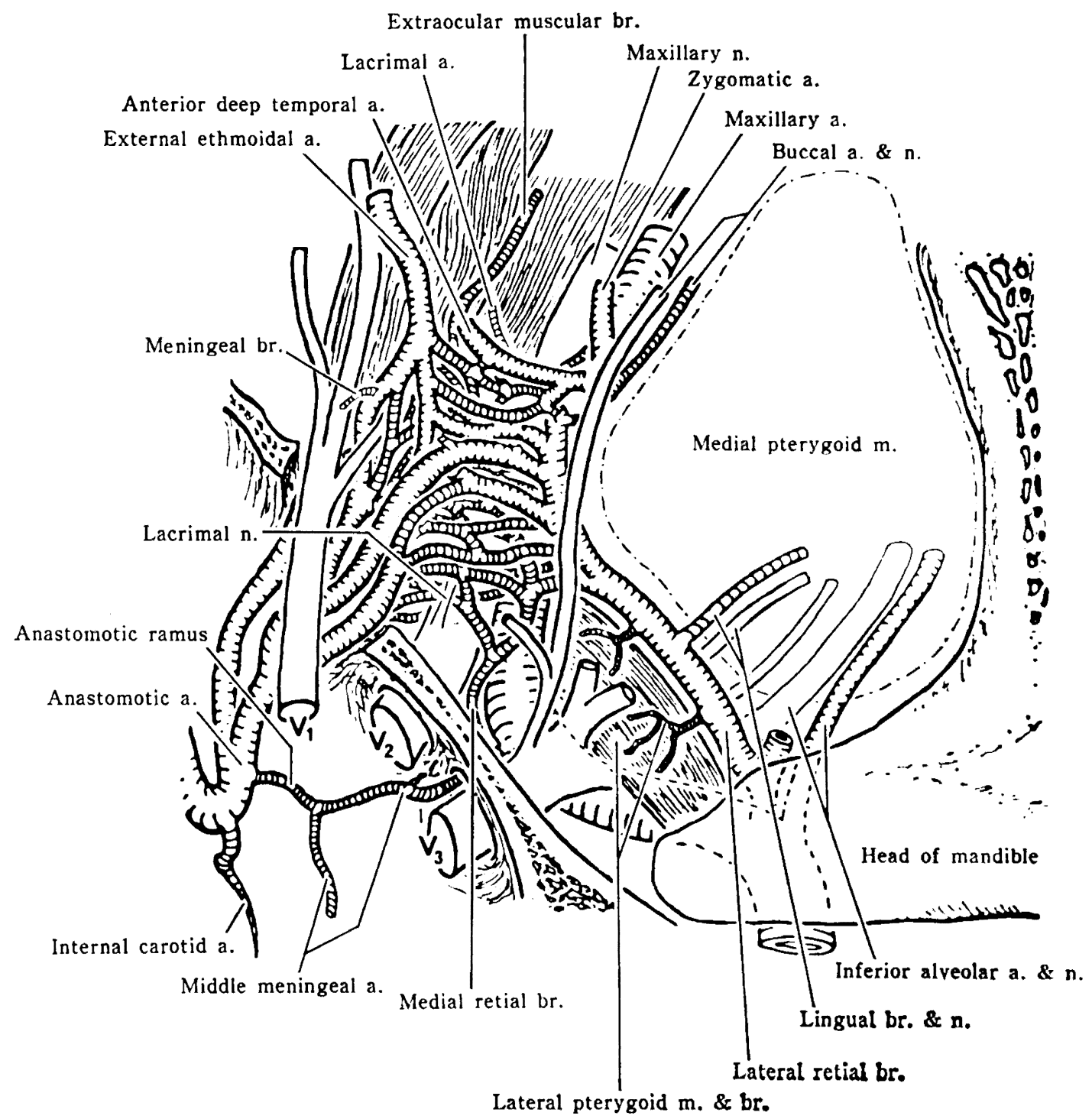

Fig. 2. Superior view of the right side. Schematic illustration of the rete mirabile and its vicinity. Part of the sphenoid bone and the articular fossa were removed. An arterial circle is formed by the lateral retial branch, the maxillary artery and the posterior part of the rete. The lateral pterygoid muscle and the mandibular nerve are held within the circle. $\left(V_{1}\right)$, Ophthalmic $\left(V_{2}\right)$, maxillary $\left(V_{3}\right)$ mandibular nerves. 

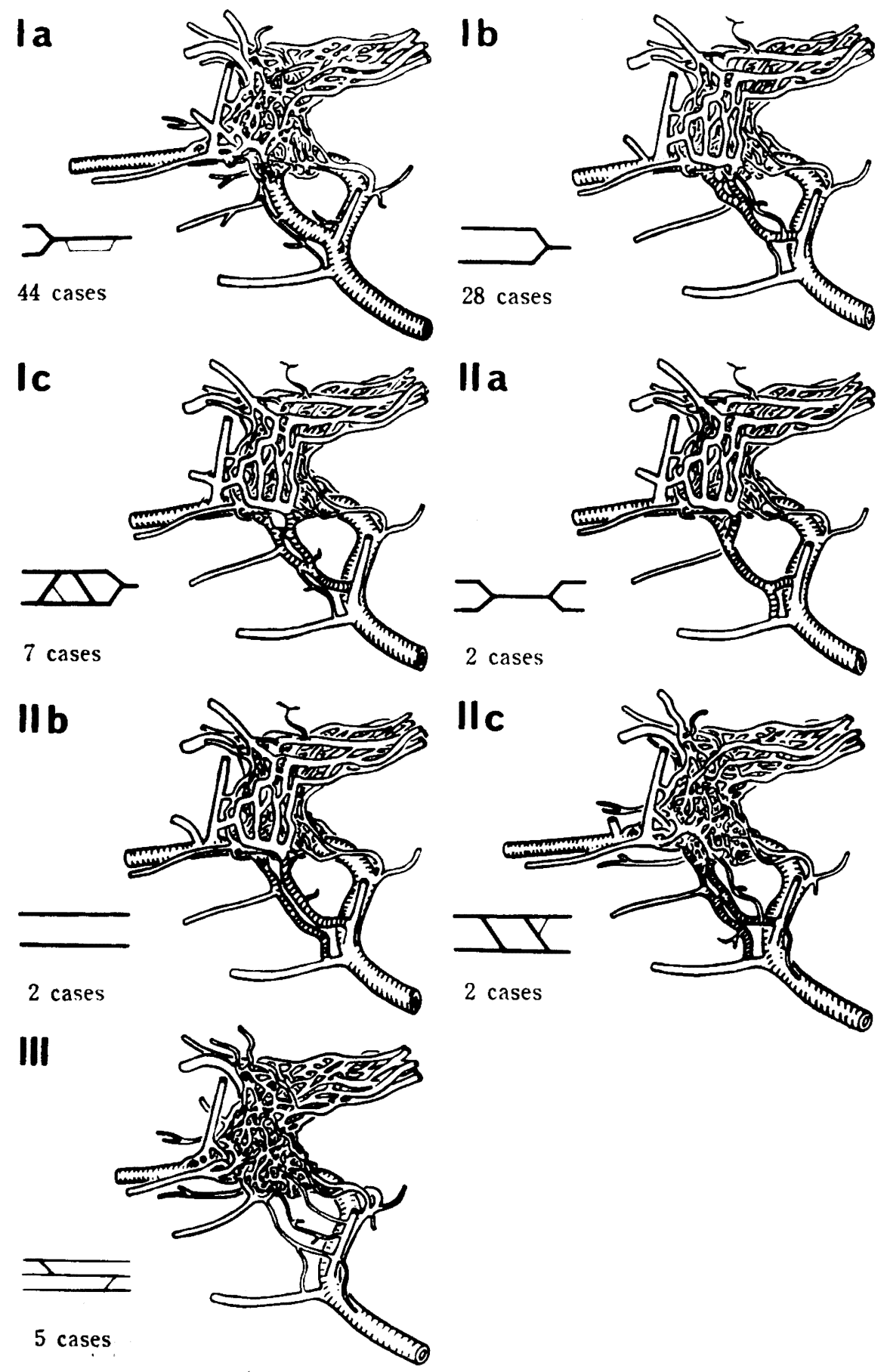

Fig. 3. Branching types I, II, and III of the lateral retial branches. 
erior deep temporal, and in the remaining one case five branches diverged from both the inferior alveolar and the posterior deep temporal. In 11 of the above 41 cases, the branch was thick $(0.30 \sim 0.80$, M. $0.58 \mathrm{~mm}$ ), and additionally a thick one arose from the posterior deep temporal (Fig. 10).

c) Course of the lateral retial branch

The lateral retial branch arising from the posterior deep temporal immediately crossed above the mandibular nerve anteriorly (Figs. 1,2) or sometimes detoured in the shape of an omega $(\Omega)$. The branch arising from the inferior alveolar crossed beneath the nerve. It ran anteromedially lateral to the lateral pterygoid muscle, with rich ramifications and anastomoses (Fig. 3), and en route gave rise to the lateral pterygoid branches in the examples observed, the lingual branch in 83 cases, the tympanic tensor branch (Davis et al. $1943)$ in 52 cases and the anterior tympanic artery (Davis et al.) in 45 cases (Fig. 17).

An arterial circle was usually formed by the lateral retial branch, the maxillary artery and the posterolateral part of the rete in the horizontal plane (Fig. 15). The former built up the lateral part of the circle, and the middle the medial part, and the last the anterior part. In this circle, the lateral pterygoid muscle was situated anteriorly and the mandibular nerve posteriorly (Figs. 2, 4).

According to the thickness, number and courses of the lateral retial branch, a subdivision into three types was made (Fig. 3). In any type, the branch ran up to about one third of the inferolateral edge of the rete which was its posterolateral corner (Fig. 15). The thick branch arriving straightly at the corner divided into superior and inferior twigs. Two branches continued as these twigs, respectively. The fine branch joined the thick branch mentioned above in most cases, or directly met the component arterial branches of the rete in its posterior part on the lateral surface.

Type I. One thick and several fine lateral retial branches (79 cases)

Ia: The thick branch, forming a loop in one case, divided into superior and inferior twigs at the posterolateral corner of the rete (44 cases, including two cases in which the thick one penetrated the rete).

Ib : The thick branch divided into superior and inferior twigs, both of which continued up to the rete (28 cases).

Ic: The thick branch divided into superior and inferior twigs, both of which continued up to the rete, anastomosing between them ( 7 cases).

Type II. Two thick and several fine lateral retial branches ( 6 cases)

IIa: Two thick branches once joined each other after their origins, but again divided into superior and inferior twigs (2 cases).

IIb : Two thick branches continued up to the rete as superior and inferior twigs ( 2 cases).

IIc: The two thick branches were similar in features to IIb, with rich ramifications and anastomoses with each other ( 2 cases).

Type III. One or several fine lateral retial branches ( 5 cases)

These joined the component branches of the rete irregularly.

The inferior twig spread in an arborescent shape inferomedially from the posterolateral corner of the rete, and formed mainly the inferior surface of the rete (Figs. 18, 25). The superior twig joined the component branches of the rete, above the destination of the inferior twig and spread into several small twigs. The main stream of the superior twig gave off ramifications superiorly in the shape of 
comb, in order to form the lateral surface of the rete (Fig. 15). The other stream passed supero- or posteromedially to form the anterior part of the above-mentioned arterial circle and the posterior part of the lateral surface of the rete (Fig. 1).

d) Branches arising from the lateral retial branches

i) Lateral pterygoid branches

These branches $(0.05 \sim 0.20$, M. $0.12 \mathrm{~mm}$ in diameter) numbered two to four (three in 49 cases, four in 29 cases and two in 12 cases). They arose from the medial, the inferomedial or the superomedial wall of the lateral retial branch medially, and were distributed to the lateral pterygoid muscle (Figs. 2, 11, 15).

ii) Lingual branch

This branch $(0.15 \sim 0.38$, M. $0.25 \mathrm{~mm}$ in diameter) arose inferoanteriorly from the inferolateral wall of the lateral retial branch in 83 cases of the examples observed (Figs. 1,16). The branch in the seven other cases arose from the posteroinferolateral part of the rete (Fig. 20). These branches ran inferoanteriorly inferolateral to the lingual nerve and medial to the medial pterygoid muscle, towards the floor of the mouth, giving off two to four medial pterygoid branches.

iii) Tympanic tensor branch (Davis et al. 1943)

This branch $(0.15 \sim 0.40$, M. $0.26 \mathrm{~mm}$ in diameter) arose from the inferomedial wall of the lateral retial branch, distal to the origin of the lingual branch or the anterior tympanic artery in 52 of the examples observed, from a short stem between the middle meningeal and the medial retial branches in 26 cases, and from the inferoposterior wall of the maxillary artery proximal to the origin of the middle meningeal of 12 cases (Fig. 17). The branch passed posteromedially beneath the lateral pterygoid muscle and the maxillary artery along the auricular canal. iv) Anterior tympanic artery (Davis et al.) (Artère tympanique inférieure of Martínez 1965)

This artery $(0.15 \sim 0.35$, M. $0.24 \mathrm{~mm}$ in diameter) arose from the inferomedial wall of the lateral retial branch, distal to the origin of the lingual branch in 45 of the examples observed (Fig. 17), and passed posteromedially beneath the lateral pterygoid muscle and the maxillary artery. In the remaining 45 cases, this artery arose proximal to the origin of the middle meningeal. In 12 of them in which the tympanic tensor branch left the maxillary, it arose proximal to its origin. The artery usually ran posteriorly to enter the petrotympanic fissure.

2) Medial retial branches

These branches consisted of superomedial and inferomedial ones. The former was seen in 78 of the examples observed, and the latter in all of them. Both branches arose in common in 27 cases (Fig. 5).

a) Superomedial retial branch

This branch $(0.25 \sim 0.70$, M. $0.43 \mathrm{~mm}$ in diameter) arose via a common trunk with the middle meningeal from the maxillary in 77 of the above 78 cases (Figs. 11, 15), and in 27 cases of them via a common trunk between the middle meningeal and the inferomedial retial (Fig. 4). In the remaining one case, it numbered two, one arising via a short stem with the middle meningeal and the other arising directly from the superior wall of the maxillary artery distal to the origin of the middle meningeal (Fig. 5).

The branch passed anteriorly in parallel with the maxillary artery and divided into medial and lateral twigs, which ran up to the superior part of the posterior corner of the rete. The lateral twig ran laterally to form the posterior part of the lateral surface of the rete with the superior twig of the lateral retial branch. The medial twig ran anteromedially to form about the posterior $1 / 3$ of the superior wall of an 


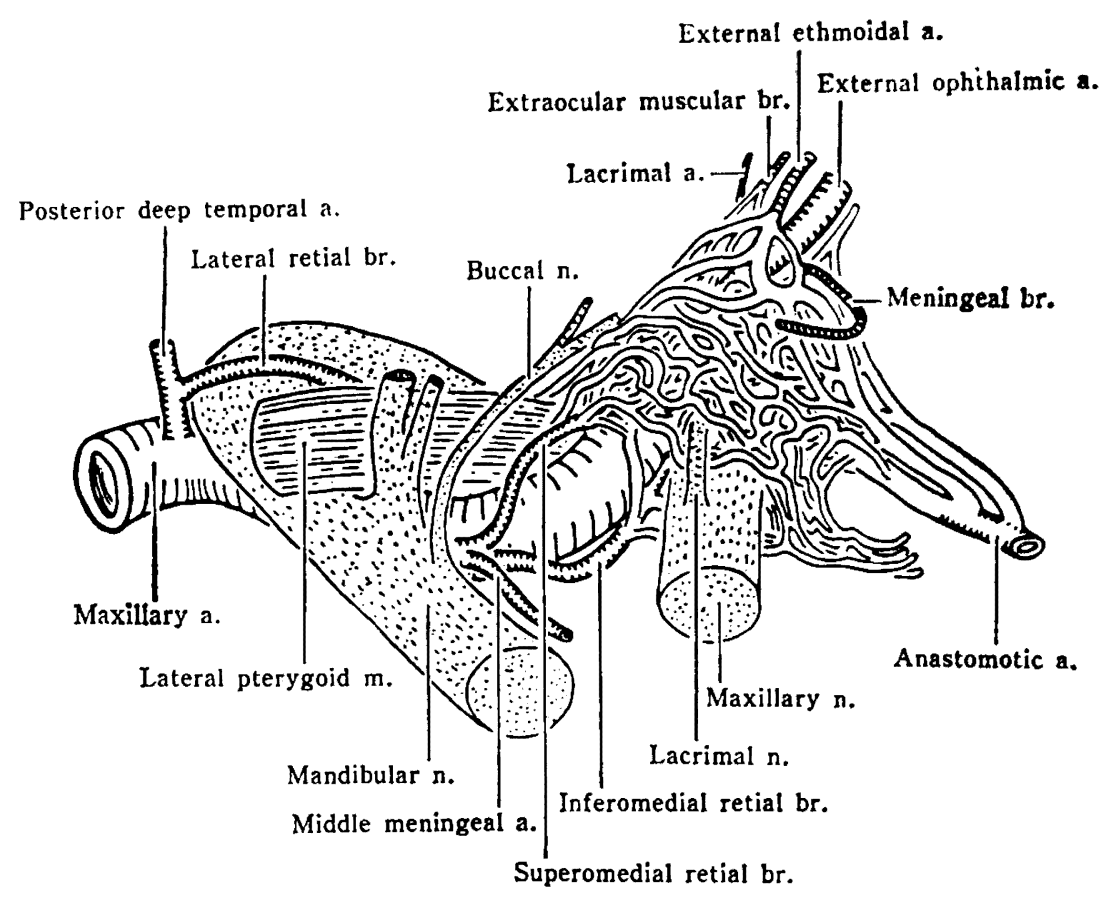

Fig. 4. Posteromedial view of the left side. Schematic illustration indicating the relations between the rete, the maxillary and the mandibular nerves and the lateral pterygoid muscle. In this drawing, the middle meningeal artery arises from the maxillary artery via a common stem between the supero- and the inferomedial retial branches.

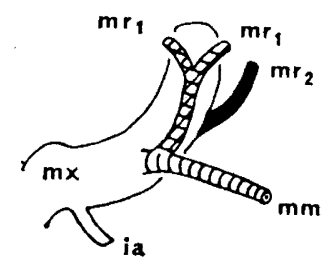

50 cases

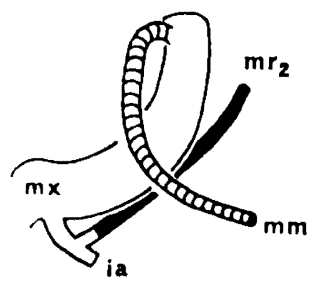

10 cases

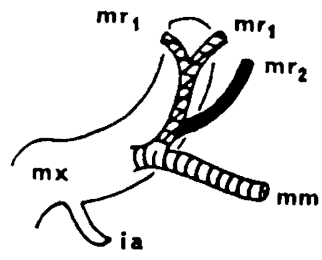

27 cases

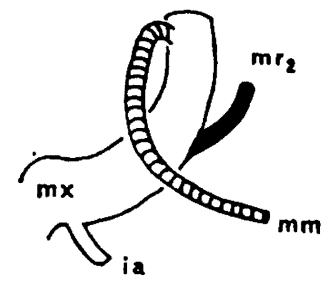

2 cases

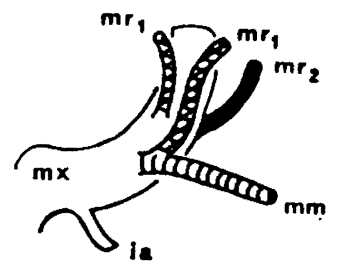

1 case

Fig. 5. Branching types of the supero- and the inferomedial retial branches. Superomedial retial branch $\left(\mathrm{mr}_{1}\right)$, Inferomedial retial branch $\left(\mathrm{mr}_{\mathbf{2}}\right)$, $(\mathrm{mm})$, Maxillary artery $(\mathrm{mx})$, Inferior alveolar artery (ia). 
arterial cylinder, which penetrated the rete surrounding the maxillary nerve, and was termed the maxillary nerve tunnel (Tunnel du nerf maxillarie supérieur of Martínez) (Fig. 6).

In the 12 cases in which this branch was lacking, the superior twig of the lateral retial branch formed this part of the rete (Fig. 18). On the other hand, when the lateral retial branch was underdeveloped, that was supplemented by twigs of the medial retial branch.

b) Inferomedial retial branch

This branch $(0.20 \sim 0.60$, M. $0.34 \mathrm{~mm}$ in diameter) arose from the maxillary artery in 80 of the examples observed. In 53 of the 80 cases, it arose directly from its inferior wall, distal to the origin of the common stem between the middle meningeal and the superomedial retial branch in 51 of them (Fig. 11); the superomedial retial branch was lacking and the middle meningeal arose from the rete in the two remaining cases (Fig. 5). In 27 of the 80 cases, this branch arose from the maxillary artery via a short stem between the superomedial retial branch and the middle meningeal artery.

The branch in the 80 cases passed anteriorly beneath the maxillary artery up to the inferior part of the posterior corner of the rete (Fig. 20).

In 10 of the examples observed, the branch arising from the lateral retial branch which left the inferior alveolar artery, ran anteroinferiorly in parallel with the maxillary artery up to that part of the rete (Fig. 5).

The branch reached the rete, repeating ramifications and anastomoses, and formed about the posterior $1 / 3$ of the inferior wall of the maxillary nerve tunnel with the inferior twig of the lateral retial branch. Thus, the posterior $1 / 3$ of the medial wall of the tunnel was formed by both the supero- and the inferomedial retial branches (Fig. 11). When this branch was underdeveloped, the formation was supplemented by the inferior twig of the lateral retial branch (Fig. 18). Conversely, when the lateral retial branch was underdeveloped, it was supplemented by the medial retial branch.

3) Anterior retial branches

These branches $(0.10 \sim 0.70$, M. $0.35 \mathrm{~mm}$ in diameter), numbered three to seven (five in 38 cases, six in 24 cases, four in 18 cases, seven in six cases and three in four cases). They arose posteriorly from the posteromedial wall of the anterior deep temporal artery $(0.35 \sim 0.80$, M. $0.55 \mathrm{~mm})$ (Figs. 1, 15). In addition to them, similar branches arose superiorly and inferiorly from the superolateral wall of the buccal artery $(0.30 \sim 0.65$, M. $0.51 \mathrm{~mm})$ in 77 cases (Figs. 1, 10), posteriorly from the posteromedial wall of the zygomatic artery (a. zygomatica of Davis et al.) in 44 cases (Fig. 1j), and superiorly and inferiorly from the superolateral wall of the maxillary artery in three cases. However, in 22 of 25 cases in which the anterior deep temporal arose from the maxillary artery in common with the zygomatic artery, this branch left only the anterior deep temporal, and from both arteries in the other three cases.

These branches arising from the anterior deep temporal and the zygomatic arteries shortly ran posteriorly towards the anterolateral margin of the rete, where they formed the anterior part of the lareral surface of the rete (Figs. 1, 15), together with the anterior retial branches arising from the buccal and the maxillary arteries superiorly and the superior twig of the lateral retial branch. Those arising from the buccal and the maxillary arteries inferiorly formed the anterior part of the inferior surface of the rete with the inferior twig of the lateral retial branch.

In 10 cases in which the branch arising from the buccal or the maxillary was lacking, the anterolateral corner of the 
rete was neither formed nor supplemented by any other banches. Accordingly, the maxillary, the buccal arteries and the superior and inferior branches of the intraretial branch in these cases were visible directly (Fig. 19).

2. Afferent arterial branches arising within the rete

Only the intraretial branches were observed as vessels arising within the rete. They numbered five to eight (eight in 56 cases, seven in 24 cases, six in eight cases and five in two cases) and were grouped into posterior, superior and inferior ones, according to the location as their origin (Figs. 6, 19, 20, 21).

1) Posterior intraretial branch

This branch $(0.35 \sim 0.80$, M. $0.51 \mathrm{~mm}$ in diameter), which numbered one in 78 cases and two in 12 cases, arose laterally from the inferolateral wall of the maxillary artery at the same height as or distal to

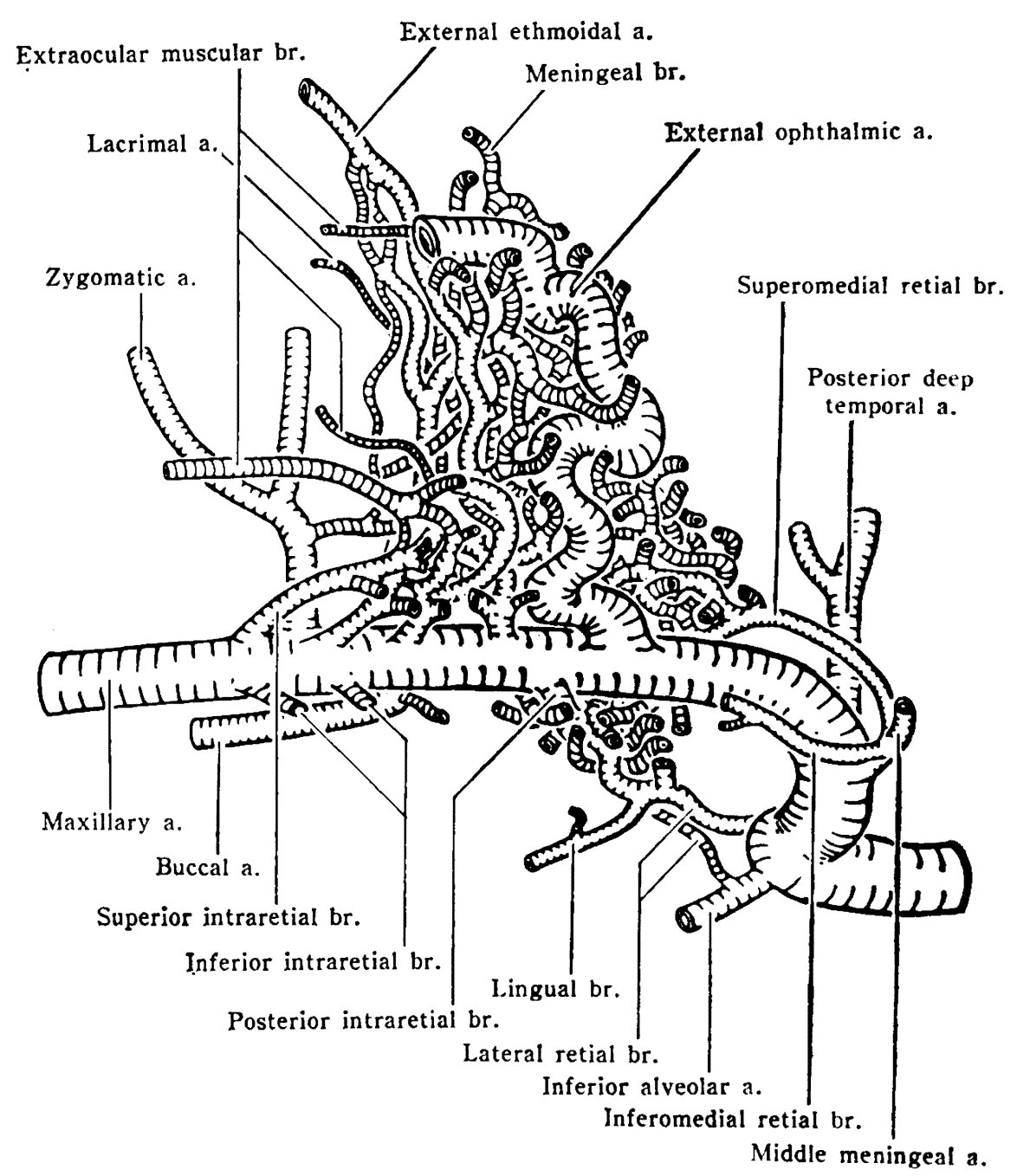

Fig. 6. Medial view of the right side. Schematic illustration indicating the internal features of the rete mirabile after removal of the medial half of the component branches of the rete (see Fig. 21). The external ophthalmic artery does not communicate with the component branches of the rete. The superior and the inferior intraretial branches arise directiy from the maxillary artery. 
the origin of the external ophthalmic artery (a. ciliaris of Davis et al.) (Figs. 6, 19), and immediately spread into superior and inferior twigs. The former branched and arched superomedially to form the posterolateral part inside the rete, and the latter medially to form the inferoposterior part inside it as well as the middle $1 / 3$ of the inferior wall of the maxillary nerve tunnel (Fig. 22).

2) Superior intraretial branches

These branches $(0.20 \sim 0.35$, M. $0.27 \mathrm{~mm}$ in diameter), which numbered two to four (three in 70 cases, four in 12 cases and two in eight cases), arose posterosuperomedially from the superomedial wall of the maxillary artery in its distal half within the rete. Distal ones arose with a strong, posterior inclination. In 17 cases, the origin of the distalmost branch was located distal to the level of the anterolateral corner of the rete (Figs. 20,21), and in five of these cases distal to the origin of the anterior deep temporal. The branch formed the superior part of the anterior $2 / 3$ of the maxillary nerve tunnel without any other branches.

3) Inferior intraretial branches

These branches $(0.20 \sim 40$, M. $0.29 \mathrm{~mm}$ in. diameter), which numbered three in 58 cases and two in 32 cases, arose from the inferomedial wall of the maxillary artery (Figs. 6, 20, 22). Distal ones arose with a strong, posterior inclination. The distalmost branch arose distal to the anterolateral corner of the rete outside it in 12 of the examples observed (Fig. 20). The branch formed the inferior part of the anterior $1 / 3$ of the maxillary nerve tunnel independently (Figs. 6, 20).

Thus, the anterior $2 / 3$ of the medial wall of the tunnel was formed by all these intraretial branches (Figs. 20,22).

II. Vascularization of the rete mirabile

The rete had four surfaces and four corners. These were the wide and flat lateral, the medial, the inferior and the narrow and irregular anterior surfaces, and the posterior (kaudoventrale Ecke of Hürlimann), the anterolateral (oroventrale Ecke of Hürlmann), the anterosuperior (orodorsale Ecke of Hürlimann) and the medial (kaudodorsale Ecke of Hürlimann) corners. Only the last of them was located in the cranium. The whole rete appeared as a type of trigonal pyramid, the vertex of which inclined anterolaterally and the inferior surface of which formed the base (Fig. 1). The maxillary artery penetrated from its posterior cornner through the anterolateral corner in parallel with the maxillary nerve medially (Fig. 12). Above all, a cylinder, termed the maxillary nerve tunnel (Tunnel du nerf maxillarie supérieur of Martínez) was formed intraretially by arterial branches. Along this tunnels the rete could be divided into superior and inferior portions (Figs. 6, 21). Above the tunnel, the lacrimal and the zygomatic nerves ( $\mathrm{nn}$. lacrimalis et zygomaticus of Davis et al.) penetrated obliquely to the superoanterior. Several small ganglia were observed superomedial and inferomedial to the maxillary nerve (Fig. 24) within the rete. They received the afferent fibers of the major petrosus nerve through the orbital fissure towards the extracranial basis. Some nervous communications were observed between the ganglia, the palatine and the zygomatic nerves. Within the rete, numerous venous branches coiled around its component arterial branches to form a kind of pterygoid venous plexus (rete mirabile conjugatum of Gillilan et al. 1963) over a small limited area.

1) Lateral surface

This surface appeared as a right triangle. Its base was the inferolateral margin and its vertex was the anterosuperior corner. However, in 85 of the examples observed, this surface consisted of a large anterolateral area and a narrow posterolateral area, since the posterolateral corner was 
formed by a thick lateral retial branch. The component arterial branches of the anterolateral surface were compressed and appeared flat in section because the surface was in tight contact with the temporal muscle (Figs. 1, 12).

The main component branches of the anterolateral surface comprised the superior twig of the lateral retial branch (Fig. 15), and additionally the superior twig of the posterior intraretial branch formed the posterior area of this surface and the anterior retial branch formed the anterior area. In 10 cases in which the anterior retial branch was lacking, the anteroinferior area of the anterolateral surface of the rete was not formed. Part of the maxillary passing within the rete was thus directly visible (Fig. 19). The posterolateral surface was composed of branches of the surperior twig of the lateral retial branch laterally, the lateral twig of the superomedial retial branch posteriorly and the superior twig of the posterior intraretial branch medially.

In five of the examples observed, only a fine lateral retial branch was seen without formation of the posterolateral corner of the rete. Accordingly, the lateral surface of the rete appeared as a simple flat plane which was in direct contact with the temporal muscle. In these cases, the surface was formed by the lateral twig of the superomedial retial branch posteriorly, the superior twig of the posterior intraretial branch medially and the anterior retial branch anteriorly.

The component branches in the lateral or anterolateral surface passed superomedially, branching and anastomosing repeatedly, towards a ridge running between the anterosuperior and the posterolateral corners to shift to the medial surface (Figs. 7, 15).

2) Medial surface

This surface was composed of the superoand the inferomedial areas, on which ir- regular convexities or concavities were seen because the well-developed anastomotic artery left them. The superomedial area formed a flat plane which contacted with the sphenoid bone, while the inferomedial area was a concave plane which contacted with the lateral surface of the basis of the orbital cone (Fig. 23). The component branches thus appeared flat in section.

The component branches of the superomedial surface, which was a continuation of the lateral surface as mentioned above, passed posteromedially through the orbital fissure, anastomosing with one another towards the medial corner, and turned to a resource of the posterosuperior group which gave rise to the anastomotic artery (Figs. 7, 27). The component branches of the inferomedial surface, particularly those forming the medial part of the maxillary nerve tunnel, passed posteromedially through the orbital fissure, anastomosing with one another towards the medial corner, and turned to a resource of the anteroinferior group which gave rise to the anastomotic artery (Figs. 7, 27).

3) Inferior surface

This surface was not flat. Its component branches were not parallel with one another, due to rich anastomoses and branchings in the shape of $Y$. They appeared round in section because they were located within adiposal tissue. The com. ponent branches of this surface originated mainly from the inferior twig of the lateral retial branch outside the rete (Fig. 25 ), and additionally from the inferomedial retial branches posteriorly and the inferior twig of the posterior intraretial branch inside the rete. All these branches passed towards the anteromedial corner of the rete to turn to a resource of the external ethmoidal and the interretial arteries (Fig. 25 ), which ran through the optic canal inferior to the same named nerve. 
4) Anterior surface

This surface appeared as a deep concavity due to the penetration of the oculomotor, the trochlear, the abductor nerves and the orbital cone (Fig. 23). The anterosuperior corner, however, appeared as a protrusion since it gave rise to the external ophthalmic artery (a. ciliaris of Davis et al.), the external ethmoidal artery and the extraocular muscular branches (Figs. 1, 7, 26). The anterolateral corner also appeared as a strong protrusion since it gave rise to the anterior deep temporal, the zygomatic and the buccal arteries (Figs. 1, 2, 7). The anteromedial corner appeared as a strong protrusion since it gave rise to the interretial artery and the communicating branch with the external ethmoidal artery (Figs. 25, 26). These three protrusions were joined with branches rather like a $\mathrm{C}$-shaped ridge from the lateral to the inferior margin of this surface (Fig. 26). In short, both the medial and anterior surfaces formed the site of origin of the efferent vessels of the rete, while both the lateral and inferior surfaces formed the receiving site of the afferent vessels.

5) Internal view of the rete

In the superior region of the rete, the posterior $1 / 3$ of the deep portion adjoining the maxillary nerve was formed by the medial twig of the superomedial retial branch, and the anterior $2 / 3$ by the superior intraretial branch. The intermediate portion, surrounding outside the deep portion, was formed by numerous communications between the superior twig of the posterior intraretial branch and the deep and superficial portions of the rete. The superficial portion, that is, the lateral and the superomedial surfaces, was formed by the component branches of the lateral surface (Fig. 21).

In the inferior region of the rete, the posterior $1 / 3$ of the deep portion adjoining the maxillary nerve, was formed by the inferomedial retial branch, the middle $1 / 3$ by the inferior twig of the posterior intraretial branch, and the anterior $1 / 3$ by the inferior intraretial branch. The intermediate portion was formed by numerous communications between the deep and superficial portions of the rete. The superficial portion was formed by the component branches of the inferior surface (Fig. 6).

It was considerably difficult to separate the deep, the intermediate and the superficial portions from one another, owing to rich communications between the component branches of each portion. The branches of the deep and the intermediate portions had rich communications with one another medial to the maxillary nerve, and formed the inferomedial surface of the rete mentioned above (Figs. 4, 11, 18), and then turned to a resource of the anteroinferior group for the anastomotic artery (Fig. 27).

The superficial portion of the superior region actually formed the lateral and superomedial surfaces, and then turned to a resource of the posterosuperior group for the anastomotic artery (Figs. 2, 7, 15, 27). The superficial portion of the inferior region formed the inferior surface, and then turned to a resource of the interretial and the communicating branch with the external ethmoidal (Fig. 25).

III. Efferent arterial branches of the rete The largest, anastomotic artery which left the large protrusion of the medial suface of the rete and serveral branches which left three corners of it, were observed.

1) Anastomotic artery (rr. retis of Nomina anatomica veterinaria 1973)

This artery was always well-developed in the 90 examples observed. The component branches of the rete first joined into six to nine confluents in parallel posteromedially to form a resource of the 
anastomotic artery (Fig. 11). This resource was composed of posterosuperior and anteroinferior groups (Fig. 27). The former was derived from the component branches of the lateral and the superomedial surfaces, and the latter from those surrounding the maxillary nerve tunnel.
Both joined into a flattened bundle, superior to the oculomotor, the trochlear and the abductor nerves, which passed through the orbital fissure posteromedially to the internal cranial basis, where the bundle confluenced into a short, anastomotic artery. This poured into the cere-

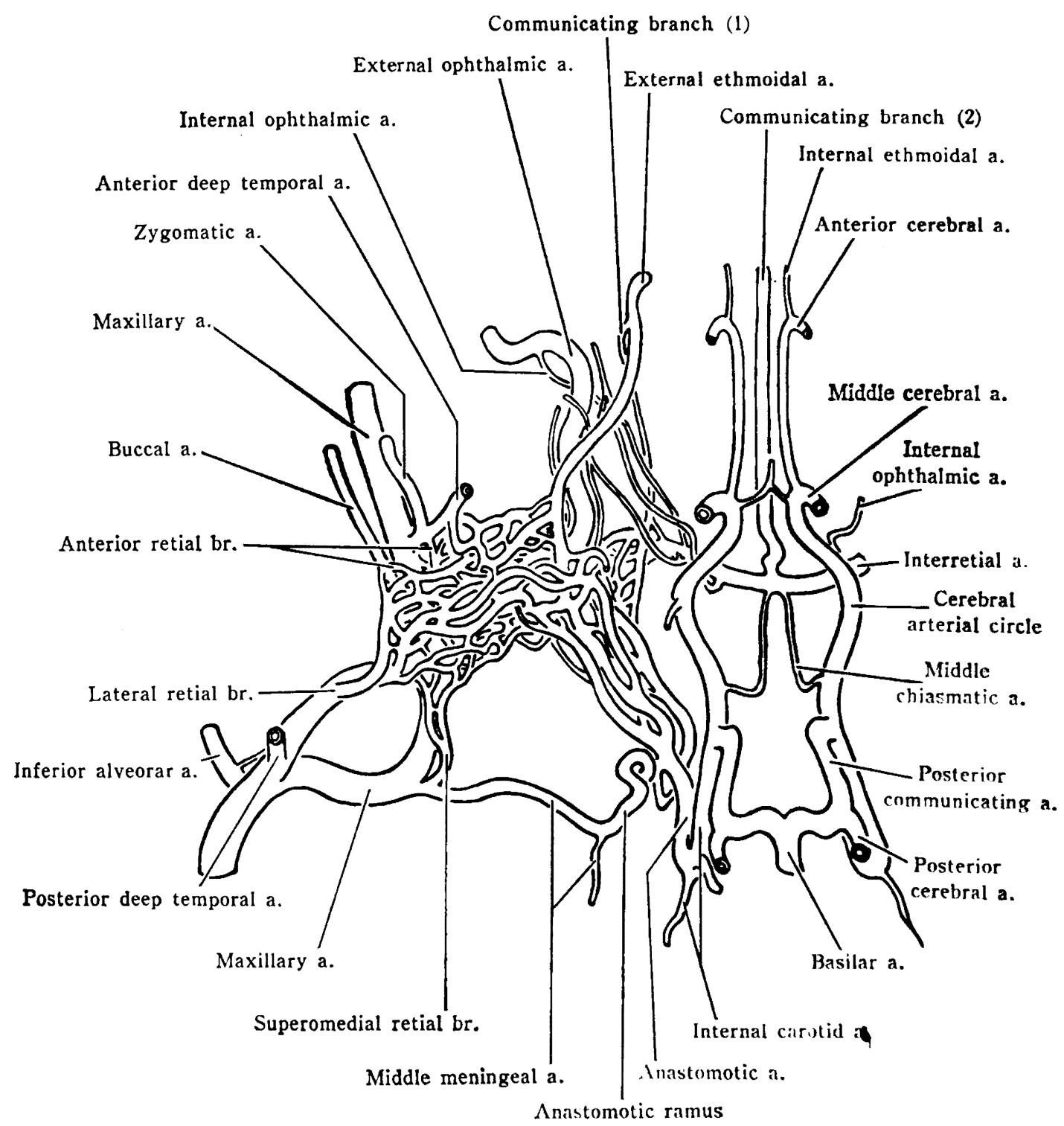

Fig. 7. Superior view of the left side. Schematic illustration of the rete mirabile, the cerebral arterial circle and their vicinity. (1) Communicating branch between the rete and the external ethmoidal artery. (2) Communicating branch between the interretial and the in. ternal ethmoidal arteries. There is an anastomotic ramus between the middle meningeal and the anastomotic arteries. 
bral arterial circle (circle of Willis of Norris 1906 and Davis et al.) via the remnant (a. carotis cerebralis of Hürlimann and rostral ramus of Gillilan 1976) of the internal carotid artery in the cranium (Fig. 7).

In 80 of the examples observed, communications were seen between both groups, and in 45 of the 80 cases were indistinguishable from each other owing to rich communications on the internal cranial basis. In the other 10 cases, no communication was seen between the groups, but each group joined into one branch independently, which confluenced into one immediately before pouring into the remnant, respectively (Fig. 27). The posterosuperior group received the anastomotic ramus of the middle meningeal artery which entered the internal cranial basis through the oval or round foramen in one case, immediately before the final confluence (Figs. 7, 15).

2) External ethmoidal artery

This artery $(0.20 \sim 0.60$, M. $0.51 \mathrm{~mm}$ in diameter) numbered one in 78 cases, and two in 12 cases. It was composed of the confluence of two to five (three in 54 cases, two in 26 cases, four in eight cases and five in two cases) component branches around the anterosuperior corner of the rete. At least one of these branches originated from the anterior retial branch of the anterior deep temporal artery (Figs. 1,15). Accordingly, the blood stream may pass through the anterior deep temporal, the anterior retial branch, the rete and the external ethmoidal artery in that order.

This artery arising anterosuperiorly penetrated the periorbita and arched anteroinferiorly medial to the superior palpebral levator muscle, sometimes forming arterial islands by anastomosing and branching. It received a communicating vessel from the anteromedial corner of the rete immediately before the ethmoidal foramen (Fig. 28). In two cases in which this artery was not developed, it was supplemented by this vessel. An arterial circle was thus formed by this vessel, the external ethmoidal artery, and the inferior and the lateral surfaces of the rete (Fig. 28). The full angiology of this artery has been studied by Shimizu (1968).

3) Extraocular muscular branches

These branches $(0.15 \sim 0.40$, M. $0.30 \mathrm{~mm}$ in diameter) numbered three to five in the examples observed (five in 48 cases, four in 34 cases and three in eight cases). Two or three of them diverged from the upper part of the anterior border of the lateral surface of the rete, and the others anteriorly and slightly laterally from the anterior border of its medial surface. They immediately penetrated the lateral area of the periorbita, or only one or two of them in parallel with the external ophthalmic artery (Fig. 28), to enter the orbital fossa to supply the extraocular muscles.

4) Meningeal branch

This branch $(0.20 \sim 0.30$, M. $0.25 \mathrm{~mm}$ in diameter), seen as only one in the examples observed, diverged medially from the superomedial surface of the rete near its anteromedial corner (Fig. 18). The branch immediately passed through a foramen in a suture between the greater and lesser wings of the sphenoid bone (Fig. 1) towards the internal cranial basis, and arched along a groove superolaterally to supply the anterior area of the middle cranial basis.

5) Lacrimal artery

This artery $(0.20 \sim 0.35$, M. $0.27 \mathrm{~mm}$ in diameter) was formed by some of the component branches of the anterior border of the lateral surface of the rete. It arose superoanteriorly from the anterosuperior corner of the rete (Figs. 5, 15), and passed anterosuperiorly superolateral to a communicating nerve (which was a branch of the maxillary nerve penetrating the rete) 
with the lacrimal nerve towards the lacrimal gland.

\section{6) Interretial artery}

This artery $(0.30 \sim 0.65$, M. $0.49 \mathrm{~mm}$ in diameter) was formed by two to five of the component branches of the inferior surface of the rete in the examples observed (Fig. 25). It left its anteromedial corner, giving off a twig to the communicating branch with the external ethmoidal, and passed posteromedially on the anteroinferior wall of the optic canal, and then anteroinferior to the optic nerve towards the internal cranial basis. Along this course, it gave raise to a communicating branch with the internal ophthalmic (Figs. 7, 29, 30) and small twigs (0.10 0.30 , M. $0.22 \mathrm{~mm}$ ) anterosuperolaterally which passed through the optic canal and communicated with the extraocular muscular branches that ran in parallel with the external ophthalmic extracranially.

This artery arched medially on the internal cranial basis and anastomosed with the opposite fellow beneath the optic chiasm. Simultaneously, it gave rise to an unpaired communicating branch (a. meningea nasalis of Hürlimann) anteriorly with the bilateral internal ethmoidal arteries (Hürlimann, Shimizu) (Figs. 7, 29, 30 ) arising from the anterior cerebral artery within the ethmoidal bone. It also gave off posteriorly a communicating branch (a. chiasmatica media of Martinez $1965)$ with the cerebral arterial circle (Fig. 30).

7) Communicating branch with the external ethmoidal artery

This branch $(0.10 \sim 0.60$, M. $0.43 \mathrm{~mm}$ in diameter) (a. anastomotica of Shimizu) was formed by two to five of the component branches of the inferior surface of the rete in the examples observed (Figs. 25, 28). It left the anteromedial corner of the rete anteriorly, giving off a communicating branch with the interretial artery, and immediately arched superiorly to anastomose with the external ethmoidal (Fig. 28) in the ethmoidal foramen. The thickness of this branch was similar to or slightly thinner than that of the external ethmoidal in 60 of the examples observed, less than a half of it in 28 cases, but it in two cases it was thicker and supplemented the external ethmoidal oppositely.

8) Temporal branches

In 54 of the examples, these branches $(0.10 \sim 0.38$, M. $0.28 \mathrm{~mm}$ in diameter) which numbered one to four (two in 28 cases, one in 17 cases, three in six cases and four in three cases), arose irregularly from the component branches of the posterolateral surface of the rete and the posterior half of its upper border superiorly. They never confluenced into one. In the other 36 cases in which the branch was lacking, it was supplemented by the posterior deep temporal artery.

IV. Arteries arising from the maxillary artery within or around the rete

1) Middle meningeal artery

This artery $(0.15 \sim 0.50$, M. $0.38 \mathrm{~mm}$ in diameter) arose from the posteromedial wall of the maxillary artery (Figs. 2, 4, 7, 15) when it bent anteriorly lateral to the oval foramen, in common with the superomedial retial branch in 51 of the examples observed, in common with the supero- and the inferomedial retial branches in 27 cases. It passed through the anterior area of the oval foramen into the internal cranial basis. In 12 cases, it arose posteriorly from the maxillary at the posterior corner of the rete (Fig. 5) and entered the internal cranial basis through the oval (11 cases) foramen or round (one case) foramen.

This artery passed posteriorly after giving off an anastomotic ramus with the posterosuperior group by which the anastomotic artery was formed (Figs. 7, 15).

2) External ophthalmic artery

This artery $(0.55 \sim 0.88, M .0 .72 \mathrm{~mm}$ in 
diameter) (a. ciliaris of Davis et al.) arose superiorly from the superomedial wall of the maxillary artery near the posterior corner of the rete as the proximalmost branch in the rete (Figs. 6, 21). Not anastomosing with any component branch of the rete, it passed first superiorly and then meandered anterosuperiorly up to the anterosuperior corner of the rete. The one or two extraocular muscular branches mentioned above which left this corner, ran anteromedially in parallel with this artery superolateral and inferomedial to it towards the eye ball (Figs. 7, 15). They received the internal ophthalmic artery (Davis et al.) inferiorly (Figs. 7, 15), where they arched laterally about $10 \mathrm{~mm}$ anterior to the rete.

The internal ophthalmic artery arose anteromedially from the inferior wall of the remnant of the internal carotid (a. carotis cerbralis of Hürlimann) after it fused to the cerebral arterial circle in 35 of the examples observed (Figs. 29, 30), and ran anterolaterally beneath the circle to enter the optic canal. It passed anterolaterally posterolateral to the optic nerve towards the orbit after receiving a communicating branch with the interretial artery (Fig. 30). In 12 of the examples observed, such an internal ophthalmic was seen, but was very thin (Fig. 29). In the other 43 cases, it was not seen but appeared as a feature that arose posterolaterally from the interretial artery via the above-mentioned communicating branch.

3) Buccal artery

This artery $(0.30 \sim 0.65$, M. $0.51 \mathrm{~mm}$ in diameter) arose from the superolateral or inferolateral wall of the maxillary artery passing in the anterolateral corner of the rete (Figs. 1, 19). In 77 of the examples observed, it gave off the anterior retial branch, in common with the anterior deep temporal in four of them, and in common with the anterior deep temporal and the zygomatic arteries in one case. In the other 13 cases, it arose independently (Fig. 19). The detailed anatomy of this artery has been studied by Hata (1967).

4) Anterior deep temporal artery

This artery $(0.35 \sim 0.80$, M. $0.55 \mathrm{~mm}$ in diameter) arose superiorly from the superior wall of the maxillary artery, immediately distal to the rete (Figs. 1, 10, 15). It arose independently in 61 of the examples observed, in common with the zygomatic in 24 cases, in common with the buccal in four cases and in common with these three in one case. This artery, giving off three to seven anterior retial branches posteriorly, ascended along the anterolateral border of the rete. The detailed anatomy of this artery has been studied by Fujimoto (1959).

5) Zygomatic artery

This artery $(0.20 \sim 0.65$, M. $0.45 \mathrm{~mm}$ in diameter: (a. zygomatica of Davis et al.) actually arose in common with other arteries as mentioned above. When its origin was independent (Fig. 19), it arose anterosuperiorly from the superior wall of the maxillary artery distal to the anterior deep temporal. When any common stem was observed (Fig. 15), it arose anterosuperiorly from its anterior wall. This artery, giving off one or two anterior retial branches posteriorly in 44 of the examples observed, usually terminated in the temporal muscle, but it was rarely so well-developed that it took the place of the superior palpebral branch of the superficial temporal artery.

\section{Discussion}

I. The rete mirabile

The "rete mirabile" of the maxillary artery in the cat has been given a variety of designations as follows: Wundernetz (Tandler 1899, Hürlimann 1913), carotid plexus (Norris 1906), carotid rete (Daniel et al., 1953), extracranial rete (Daniel et al., Martínez), and rete mirabile (Hürli- 
mann, Gillilan et al. 1963, Martínez). Two kinds of designations for the rete have thus been used by Hürlimann, Daniel et al. and Martínez. Ikoma (1956) emphasized the role which the rete played in the main blood supply to the orbital contents, and termed it the orbital arterial plexus. Davis et al. (1943) described the internal rete intracranially and the external rete extracranially in the cat, as seen in the goat. The present author, however, has been unable to find any network which may correspond to the internal rete described by them. Daniel et al. indicated that the external rete was better termed the extracranial rete since he also did not find the internal rete. The rete of the cat was recorded as the rete mirabile a. maxillaris in Nomina anatomica veterinaria (N. A. V. 1973). The present author has been confident of the appropriateness of this nomenclature in N. A. V. since the resources of the component vessels of the rete are clearly expressed by it. Recently, Nickel et al. (1976) used it in their publication.

The course and ramifications of the maxillary artery in the cat are similar to those in the dog (Fig. 31), except for the presence of the rete mirabile. First, a limited part of the rete is formed by the intraretial branches arising from the maxillary artery. This part, located in the center of the rete, rather like a nucleus of it, is termed the deep portion and contributes to the origin of the anastomotic artery after surrounding the maxillary nerve. It develops into a larger, superficial portion, rather like a shell of the rete, on account of the inflows of many afferent vessels from the inferior alveolar and the posterior deep temporal arteries as the proximalmost resource, the middle meningeal, the buccal and the anterior deep temporal and the zygomatic arteries as the distalmost resource. Between the deep and the superficial por- tions, rich communications exist to form the intermediate portion. Both the superficial and the intermediate portions contribute by all means to form the resource of the anastomotic artery. The superficial and the deep portions were termed the zones systémiques by Martínez, in which the origins of the component branches were clear, and the intermediate portion zones diffuse, in which that of each component could not be separated.

The present author represents the rete as a kind of pyramid in form, each surface and corner of which has been designated by Hürlimann and in this paper. Angiologically, all its corners are more important than all its surfaces, since they include the destinations of the afferent vessels as well as the origins of the efferent vessels. It is considered therefore that each surface represents no more than a confluence of various arterial passages between the destinations and the origins. The medial corner (kaudodorsale Ecke of Hürlimann), in particular, which is formed by the confluence of a majority of the component vessels of the rete, protrudes posteromedially to give rise to the anastomotic artery, being the largest of the efferent vessels. Accordingly, it can be said without exaggeration that the rete of the cat plays an important role as a major blood supply route to the brain in place of the degenerated and obturated internal carotid artery.

II. Afferent arterial branches of the rete Daniel et al. gave a simple description of these branches. Martinez termed the lateral retial branches the artère basale latérale, and the medial retial branches the artère apicale. He made a detailed statement regarding the formation of the rete, attaching great importance to both arteries. In the present study, his finding that all four kinds of afferent vesselsthe lateral, the medial, the anterior and 
the intraretial--should be indispensable to form the rete, was confirmed.

No description was given for the lateral retial branches by Tandler. The communicating vessel between the rete and the posterior deep temporal artery was noted by Hürlimann. Davis et al. mentioned that the anterior tympanic artery in two cases diverged from this communicating vessel, which was illustrated as an anastomosis between the rete and the inferior alveolar artery. Fujimoto (1959) designated it r. communicans posterior as a simple communication with the rete. Daniel et al. and Martínez gave clear descriptions that this branch was one of the afferent vessels of the rete.

The lateral retial branch is the thickest and most important of the four afferent vessels and fills up the other underdeveloped fellows in many cases. It participates mainly in the formation of the posterosuperior group for the resource of the anastomotic artery. When the lateral retial branches number more than two, various interesting features are seen between them. The more the number of them incrases, the more the thickness of them decreases, and vice versa. The branch is actually thick in the case of only one or two; one is similar to the maxillary artery in thickness and the other is much smaller. Such a combination could maintain a definite volume of blood supply to the brain from the maxillary artery via the rete.

Related to the origin of the lateral retial branch, the posterior deep temporal arising from the maxillary artery at the posterior, proximal end of the rete, was found only in one case. This feature is interesting and significant from the angiological viewpoint. Even in such a case, the posterior deep temporal may arise from the maxillary artery as well as the lateral retial from the posterior deep temporal in the embryonic stage (Fig. 8a). On account of the disappearance of a route between the maxillary artery and the basis of the posterior deep temporal, the blood stream may proceed to the lateral retial branch via the component branches of the rete from the posterior retial branch, and then into the posterior deep temporal. As a result of these process, such an interesting route should be formed as shown in Fig. 8b.

Daniel et al. mentioned that the lateral
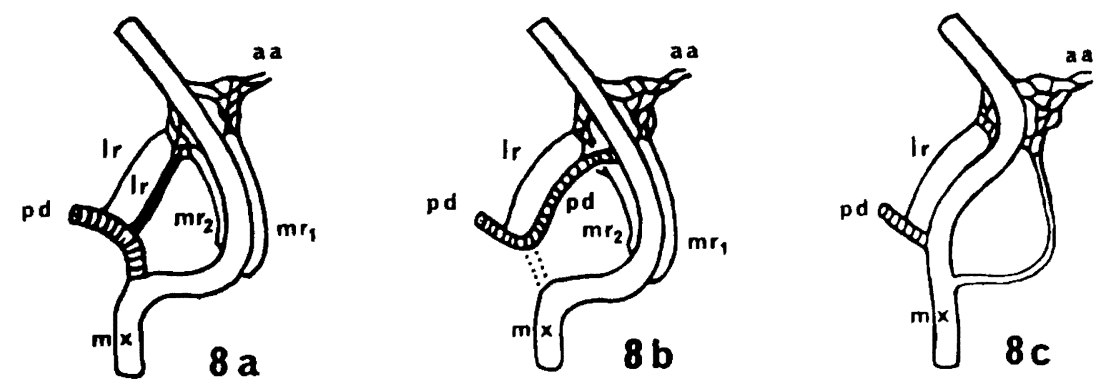

Fig. 8. Schematic illustrations of the posterior deep temporal artery showing its origin and the adjacent vessels.

8a. This artery arises from the maxillary artery, immediately distal to the origin of the inferior alveolar artery or in common with it (see Fig. 16).

8b. This artery arises from the maxillary artery at the posterior, proximal end of the rete, and was observed in one case (see Fig. 14). The dotted line indicates part of the basis of the posterior deep temporal artery which has disappeared.

$8 \mathrm{c}$. This artery, arising from the thick, lateral retial branch and penetrating the rete in place of the thin, maxillary artery, was observed in two cases (see Fig. 13). 
retial branch formed the inferior portion of the rete. Martínez presented detailed findings on its ramifications and distribution features and its origin at the meeting area between the mandibular nerve and the maxillary artery. Clear data were obtained in this study that an arterial circle is formed by the lateral retial, the maxillary and the posterior part of the rete, and the lateral pterygoid muscle and the mandibular nerve are held with it.

The relations between the lateral pterygoid muscle, which is tiny and underdeveloped, and the maxillary artery in the cat are similar to those in the dog. The artery in the cat usually passes medial to the muscle, and that in the dog inferior to the insertion of the muscle towards the alar canal (Suwa 1978). The artery in the crab-eating monkey, however, passes forwards lateral to the lower head of the muscle (Suwa 1981). In the cat, the lateral retial branch always takes a similar course to the maxillary artery of the above-mentioned species, that is, anteromedially lateral to the muscle up to the rete. In cases in which the branch is thick, it arises via a common stem between the anterior tympanic tensor and the posterior deep temporal arteries, sometimes with the inferior alveolar. In only two of the examples observed, was the lateral retial branch extremely well-developed (Fig. 8c), but the maxillary artery was extremely underdeveloped and fused in the rete. The branch in such cases gives rise to the branches mentioned above and continues as the infraorbital artery after penetrating the rete. This particular type of lateral retial branch accurately follows the courese and ramifications of the usual maxillary artery in the monkey and mostly in man. In short, the lateral pterygoid muscle and the mandibular nerve are situated between the lateral retial branch laterally and the maxillary artery medially. Such features could be seen in other species if the duplicate maxillary artery was present.

The medial retial branch is not mentioned by Tandler and Hürlimann, but illustrated only by Davis et al. Daniel et al. stated that it arose as the proximalmost of the afferent vessels. Martínez first termed it the artére apicale and made detailed observations. However, he did not give any clear statement on the origin of the branch with the exception of the formation of the maxillary nerve tunnel. In this study, it was confirmed that the anterior $2 / 3$ of the tunnel is formed by the intraretial branch, and the medial retial branches formed only its posterior $1 / 3$.

The anastomotic ramus arising from the middle meningeal artery makes a communication between it and the internal carotid artery, as observed in the dog. Since the blood supply to the internal carotid is mostly through the rete in the cat, the middle meningeal plays an important part in the parent artery of the medial retial branches.

The medial retial branches are in close relation with the lateral retial branch in their development. In cases in which the middle meningeal arises at the posterior corner of the rete, because the superomedial retial branch is lacking, it is supplemented by the superior twig of the lateral retial branch. The inferomedial retial branch arises directly from the maxillary artery or the lateral retial branch. When the latter is underdeveloped, it is supplemented by the former. On the basis of such relationships between both branches the medial retial branch is essential for the formation of the rete.

The anterior retial branches were not described by Tandler, Hürlimann, Davis et al. or Daniel et al. Fujimoto (1959) reported that they were component branches flowing into the anterior deep temporal artery. Martínez stated 
that the branches were anastomoses collatérales between the lacrimal and the anterior deep temporal. Hata (1967) in his work on the buccal artery reported that the branches numbered one to five and arose from the rete and flowed into the buccal. Such vessels mentioned by these workers are designated as anterior retial branches in the present paper. These are located close to the basis of the anterior deep temporal, the zygomatic, and the buccal arteries in all cases. Such relations may make the blood supply easy to the rete from the maxillary artery. In contrast to the intraretial branches, these branches form the anterior part of the rete, although the intraretial branches form mainly the anterior $2 / 3$ of the maxillary nerve tunnel. Accordingly, it can say that these branches are independent ones of the afferent vessels of the rete.

The intraretial branches were not described by Tandler, Hürlimann or Davis et al. They were termed the pedicule afférent distal by Martínez since they arose from the maxillary artery close to the distal end of the rete. However, he considered that they were communicating branches between the maxillary artery and the component branches around the maxillary nerve tunnel. Daniel et al. indicated that they represented the main vessel for the formation of the rete and others as the accessory vessels. In the present paper, however, these are considered basic for the formation of the rete since they occurred in the examples observed and they form the anterior $2 / 3$ of the maxillary nerve tunnel and turn to the anteroinferior group for the anastomotic artery. They can be grouped into the posterior, the superior and the inferior, according to the location of their origins. The location of the posterior intraretial branch is equal to the destination of the lateral retial branch on the rete, where it forms the posterolateral part of it me- dially and the lateral retial branch la terally. Accordingly, this part is supplemented by the medial retial branch and the posterior intraretial branch when the lateral retial branch is underdeveloped. The origins of the superior and the inferior intraretial branches are located in the anterior part of the rete, indicating that these serve to send the rete a great volume of blood as one of the afferent vessels. While the anterior retial branches finally turn to the posterosuperior group for the anastomotic artery, the intraretial branches form part of the maxillary nerve tunnel as well as the anteroinferior group for it.

\section{Efferent vessels of the rete}

Hürlimann, Davis et al. and Gillilan et al. $(1963,1976)$ have presented descriptions of the efferent vessels. The anastomotic artery was termed the distalen Reteäste by Hürlimann, and subsequently was called the a. anastomotica by Davis et al., Daniel et al. and Martiínez (1965). However, it was designated the rr. retis, which passed through the orbital fissure and formed a communication between the maxillary artery and the cerebral arterial circle, in Nomina anatomica veterinaria and by Nickel et al. It corresponds to the r. anastomoticus cum a. carotis interna (a. anastomotica of Daniel et al. and Miller 1964) of the external ophthalmic artery in the dog. They also stated that the middle meningeal in the dog and cat gave rise to the r. anastomoticus cum a. carotis interna. Daniel et al., Miller and Furuhara (1974) stated that the r. anastomoticus in the dog was a communication between the middle meningeal and the a. anastomotica.

On the basis of the present findings, it seems proper that these vessels should be named the a. anastomotica ( $r r$. retis in N.A.V.) and r. anastomoticus (r. anastomoticus cum a. carotis interna in N.A.V.), both in the cat and the dog. The external ophthalmic artery in the dog arises 
from the maxillary or the orbital artery (a. orbitalis of Miller) between the origins of the middle meningeal and the anterior deep temporal, and divides into the anastomotic (r. anat. cum a. carot. int.), the external ethmoidal and the extraocular muscular branches. The anastomotic artery in the dog is usually one which terminates in a short stem to communicate with the internal carotid artery, even if it rarely makes complicated ramifications in a plane (Fig. 31), and then receives the anastomotic ramus of the middle meningeal intracranially. On the other hand, the anastomotic artery in the cat forms a more complicated, threedimensional communication than that in the dog. The description in N.A.V. is that the artery flowed directly into the cerebral arterial circle. The findings of the present author, however, suggest that the artery sends a great volume of blood via the remnant of the internal carotid to the circle, based on data obtained in the survey on newborn cats. Markesbery et al. (1962) mentioned that the rete mirabile was not in the arterial pathway to the cat brain, although the present author could not agree with that. The description in N.A.V., that the $r$. anastomoticus of the middle meningeal communicated with the internal carotid would not be correct, but practically it communicates with the a. anastomotica as mentioned before.

The interretial artery was described as the a. ophthalmica interna by Hürlimann. He stated that this artery and the rete were communicated with the r. anastomoticus. Davis et al. and Daniel et al. termed it the a. ethmoidalis interna, by which the retia of both sides were communicated with each other and from which an unpaired vessel diverged forwards into the ethmoidal fossa. Ikoma (1956) desscribed it as the communicating artery between the right and left orbits. Martínez (1965) first called it the artéria interreti- cularis. The present author is hesitant to call it the internal ethmoidal artery, but prefers to call it the interretial artery like Martínez.

A stout, internal ophthalmic artery was seen to arise from the cerebral circle in 35 of the examples, and reached the orbit after sending off a communicating branch to the interretial artery in the optic canal. However, in 12 other cases the region between the cerebral circle and the interretial artery was extremely thin, and the origin of the internal ophthalmic was lacking in most cases. In such cases, the internal ophthalmic seemed to be originated from the interretial artery. Based on these features, Hürlimann could perhaps call the interretial artery the internal ophthalmic artery. Davis et al. mentioned that a small twig arising from the anterior part of the cerebral circle was the internal ophthalmic, which was lacking in six of 12 examples observed. Daniel et al. did not observe such a small twig. Martínez reported a vessel similar to the internal ophthalmic described in this paper in one case of 14 examples observed. Gillilan (1976) reported a thin, internal ophthalmic.

The external ophthalmic arises from the maxillary artery within the rete, and communicates with the internal ophthalmic but not with the rete. The extraocular muscular branches arise directly from the rete.

The interretial artery described in this paper was termed the a. ethmoidalis interna by Davis et al. and Daniel et al. This internal ethmoidal artery is actually a paired vessel arising forwards from the anterior cerebral artery, as described by Hürlimann and Shimizu (1968), also similar to that in the dog. Thick anastomoses are seen between the internal and the external ethmoidal arteries and an unpaired vessel (a. meningea nasalis of Hürlimann) arising from the interretial 
artery. Some workers have given rather indefinite descriptions of the internal ethmoidal artery.

The external ethmoidal has been studied under the same nomenclature in many papers. However, Davis et al., Daniel et al. and Martínez did not state that this artery received a communicating branch (a. anastomotica of Shimizu) arising from the rete, in contrast to the description of Ikoma.

\section{Acknowledgements}

The author wishes to express his sincere gratitude to Professor Y. Ohta for critically reading the manuscript, and also to Assistant Professor T. Tokioka and all staff members of the Deparment of Anatomy for their invaluable assistance. He also thanks Professor S. Suzuki, Kyoto University School of Literature, for translating the articles written in French.

\section{Literature cited}

1) Daniel, P.M., J.D.K. Dawes \& M.M.L. Prichard: Studies of the carotid rete and its associated arteries. Philos. Trans. Roy. Soc. London, 237 (B) : 173-208, plates 12 19, 1953.

2) Davis, D.D. \& H.E. Story: The carotid circulation in the domestic cat. Zool. Series Field Mus. Nat. Hist., 28 : 1-47, 1943.

3) Fujimoto, T.: Cubical anatomy of several ducts and vessels by injection method of acrylic resin. V. Arterial distribution of the temporal muscle in some mammals. Okajimas Fol. Anat. Jap., 33: 389-424, 1959.

4) Furuhara, H.: On the middle meningeal artery of the dog, referred to its origin and the r. anastomoticus. Okajimas Fol. Anat. Jap., $51:$ 231-250, 1974.

5) Gillilan, L. A. \& W.R. Markesbery: Arteriovenous shunts in the blood supply to the brains of some common laboratory animals-with special attention to the rete mirabile conjugatum in the cat. J. Comp. Neurol., 121: 305-311, 1963.

6) Gillilan, L.A.: Extra- and intra-cranial blood supply to brains of dog and cat. Am. J. Anat., 146: 237-253. 1976.

7) Hata, Y.: Stereological studies on several ducts and vessels by injection method of acrylic resin. XVII. On the buccal artery in some mammals. Okajimas Fol. Anat. Jap., 43 : 331-361, 1967.

8) Hürlimann, R.: Die arteaiellen Kopfgefässe der Katze. Intern. Mschr. Anat. Physiol., 29: 371-442, 1913.

9) Ikoma, K.: Studies on the vascularisation of the inside of the orbit of mammalia. Chapter III : In cats. J. KUR. M. A., 19: 337-353, 1956. (in Japanese)

10) Markesbery, W. R. \& L.A. Gillilan: Functional analysis of the deep facial plexuses in some common laboratory animals, with special attention to the rete mirabile of the cat. Anat. Rec., 142: 255, 1962.

11) Martínez, P.: Le système artériel de la base du cerveau et l'origine des artères hypophysaires chez le chat. Acta Anat., 61: 511-546, 1965.

12) Ibid.: Sur la morphologie du réseau admirable extracrânien. Acta Anat., 67: 24-52, 1967.

13) Miller, M.E., G.C. Christensen \& H.E. Evans: Anatomy of the Dog. W.B. Saunders, Phila. and London, 292-316, 1964.

14) Nomina Anatomica Veterinaria: Published by Intern. Comm. on Veterin. Anat. Nomen., 2nd. ed., revised in 1975, Holzhausen's Succ., Vienna, 1973.

15) Norris H.W.: The carotid arteries and their relation to the circle of Willis in the cat. Proc. lowa Acad. Sci., 13: 251255, 1906.

16) Nickel, R., A. Schummer \& E. Seiferle : Lehrbuch der Anatomie der Haustiere. Bd. III, Verlag Paul Parey, Berlin \& Ham. burg, 108-121, 1976.

17) Shimizu, E.: Stereological studies on several ducts and vessels by injection method of acrylic resin. XX. On the ethmoidal artery in some mammals. Okajimas Fol. Anat. Jap., 45: 99-141. 1968.

18) Suwa, F., S. Tominaga \& H. Kumagai : 
On the posterior deep temporal artery of the dog. Okajimas Folia Anat. Jpn., 55: 255-264, 1978.

19) Suwa, F.: The posterior deep temporal artery of the crab-eating monkey. Okajimas Folia Anat. Jpn., 57 : 347-368, 1981.

20) Tandler, J.: Zur vergleichenden Anatomie der Kopfarterien bei den Mammalia. Denkschr. Kais. Akad. Wiss. Mathematisch-naturw. Klasse, Wien, 67: 711-
$712,1899$.

21) Taniguchi, Y., Y. Ohta \& S. Tajiri : New improved method for injection of acrylic resin. Okajimas Fol. Anat. Jap., $24: 259-267,1952$.

22) Taniguchi, Y., Y. Ohta, S. Tajiri, H. Okano \& H. Hanai: Supplement to new improved method for injection of acrylic resin. Okajimas Fol. Anat. Jap., 27 : 401406, 1955.

\section{Key to Abbreviations}

\author{
aa : Anastomotic artery \\ $\mathrm{aa}_{1}$ : Posterosuperior group for the anasto- \\ motic artery \\ $\mathrm{aa}_{2}$ : Anteroinferior group for the anasto- \\ motic artery \\ ad : Anterior deep temporal artery \\ ar : Anterior retial branch \\ ba : Buccal artery \\ cc : Cerebral arterial circle \\ ee : External ethmoidal artery \\ eo : External ophthalmic artery \\ ia : Inferior alveolar artery \\ ic : Internal carotid artery \\ ie : Internal ethmoidal artery \\ in : Interretial artery \\ io : Internal ophthalmic artery \\ $\mathrm{ir}_{1}$ : Superior intraretial branch \\ $\mathrm{ir}_{2}$ : Inferior intraretial branch \\ $\mathrm{ir}_{3}$ : Posterior intraretial branch \\ la : Lacrimal artery \\ Ib : Lingual branch \\ Ir : Lateral retial branch \\ $1 r_{1}$ : Superior twig of the lateral retial branch \\ $\mathrm{Ir}_{2}$ : Inferior twig of the lateral retial branch
}

lp : Lateral pterygoid branch

$\mathrm{mb}$ : Meningeal branch arising from the rete

$\mathrm{mm}$ : Middle meningeal artery

$\mathrm{mr}$ : Medial retial branch

$\mathrm{mr}_{1}$ : Superomedial retial branch

$\mathrm{mr}_{2}$ : Inferomedial retial branch

$\mathrm{mx}$ : Maxillary artery

ob : Extraocular muscular branch

pd : Posterior deep temporal artery

re : Communicating branch between the rete and the external ethmoidal artery

ri : Communicating branch between the interretial artery and the internal ethmoidal artery

rm : Anastomotic ramus between the middle meningeal and the anastomotic arteries

za : Zygomatic artery

C : Head of mandible

L : Lateral pterygoid muscle

$M$ : Medial pterygoid muscle

MD : Mandibular nerve

MX : Maxillary nerve

$\mathrm{R}$ : Rete mirabile of the maxillary artery

- Direction of snout 


\section{Explanation of Figures}

\section{Plate I}

Fig. 9. Lateral view of the left side. Disseetion specimen around the rete. Two, thick, lateral retial branches arise from the anterior wall of the posterior deep temporal artery and pass anteromedially lateral to the lateral pterygoid muscle above the mandibular nerve up to the posterolateral corner of the rete. The inferior alveolar (A) and the buccal (B) nerves run in parallel with the respective satellite arteries. $\times$ ca.4.3.

Fig. 10. Lateral view of the right side. Two, thick, lateral retial branches arise from the posterior deep temporal and the inferior alveolar arteries, respectively. The anterior retial branches arise from the buccal and the anterior deep temporal arteries. $\times$ ca.4.0.

Fig. 11. Posteromedial view of the left side. The maxillary artery gives rise to a common stem between the middle meningeal and the superomedial retial branch, and the inferomedial retial branch distal to it. The supero- and the inferomedial retial branches form the medial wall of the maxillary nerve tunnel. The lateral pterygoid branch diverges from the lateral retial branch. $(※)$ The posterior end of the tunnel. $(\star)$ The passage for the oculomotor, the trochlear and the abductor nerves and the extraocular muscles. $\times$ ca.5.3.

Fig. 12. Right side. Horizontal section through the maxillary artery. The maxillary nerve and artery and the mandibular nerve are located at the same level. The maxillary nerve and artery penetrate the rete. The middle meningeal artery passes through the oval foramen anterior to the mandibular nerve. $\times$ ca.2.7.

Fig. 13. Superior view of the left side. In two of the examples observed, an extremely thick, lateral retial branch penetrated the rete, just as the maxillary artery does, and continued as the infraorbital artery. A vessel $(\leftarrow)$ which took the same course as the usual maxillary artery, terminated as the medial retial branch (see Fig. 8c). × ca.4.2.

Fig. 14. Lateral view of the left side. In only this one of the examples observed, the posterior deep temporal artery arose from the maxillary artery at the posterior end of the rete, and gave rise to a fine lateral retial branch and a communicating branch $(\uparrow)$ with the inferior alveolar artery (see Fig. 8b). $\times$ ca.3.9. 


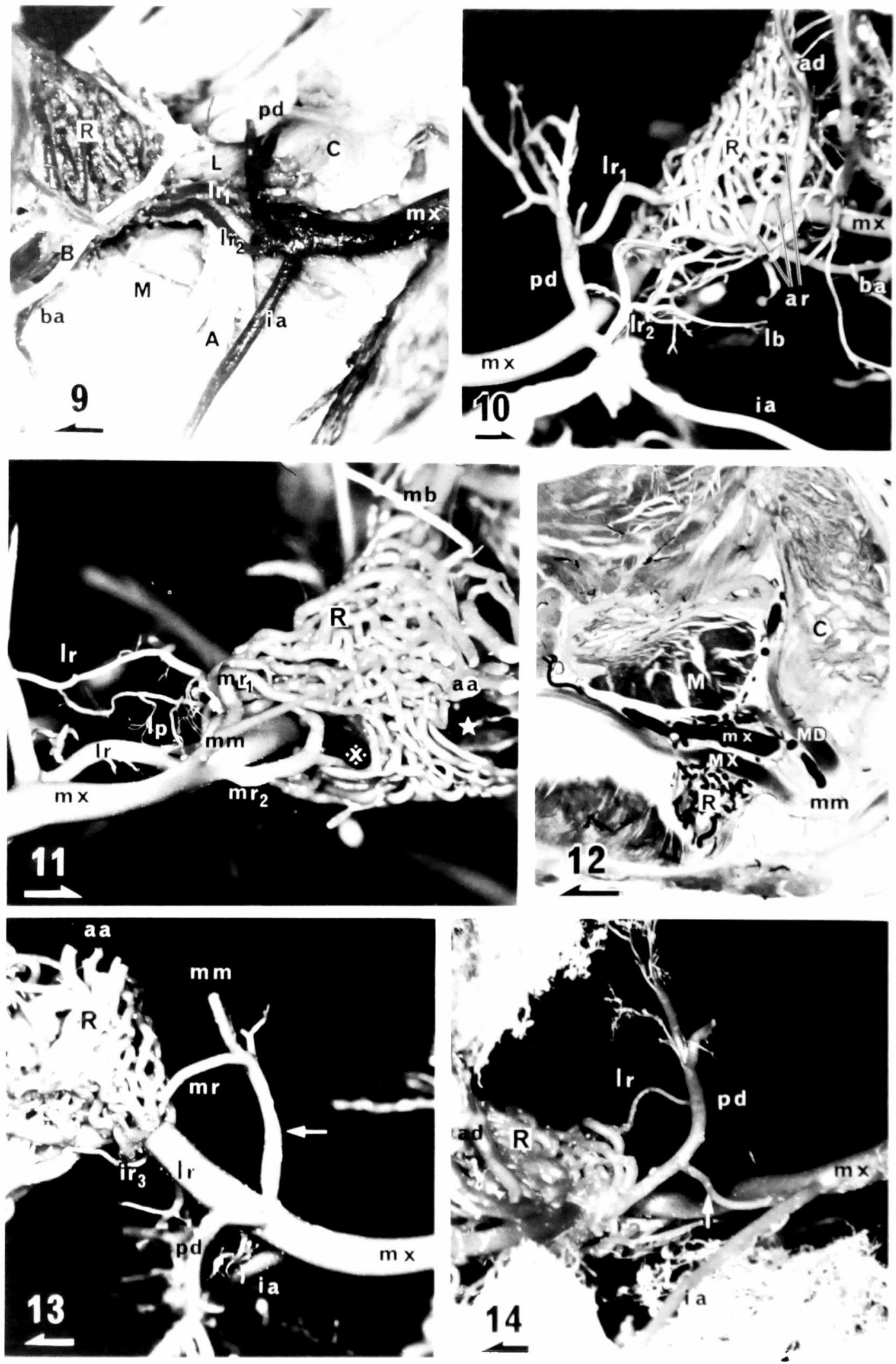

Akimichi Takemura 


\section{Plate II}

Fig. 15. Superior view of the left side. An arterial circle (※) is formed by the maxillary and the extremely thick, lateral retial branch and the posterior part of the rete. A superior twig of the lateral retial branch runs anteriorly lateral to the maxillary artery, giving off several twigs in the shape of a comb superiorly. The anterior retial branches arise from the anterior deep temporal and the zygomatic arteries. The anastomotic artery flows into the internal carotid artery as a short stem $(i)$. (pc) The posterior communicating artery. $\times$ ca.3.7.

Fig. 16. Lateral view of the right side. The posterior deep temporal artery arises from the maxillary artery in common with the inferior alveolar artery (see Fig. 8a). Six, fine, lateral retial branches, giving off the lingual branch, diverge from the posterior deep temporal. The temporal branch (tb) arises superiorly from the component branches of the rete near the posterior part of the rete. $\times$ ca. 5.1.

Fig. 17. Inferior view of the right side. The tympanic bulla was removed. The anterior tympanic artery (ta) arises posteriorly from the inferior wall of the lateral retial branch im. mediately before it bifurcates. The tympanic tensor branch ( $t t)$ arises from the posteroinferior wall of the maxillary artery proximal to the origin of a common stem between the middle meningeal and the medial retial branches. ( $\mathrm{T}$ ) The tympanic tensor muscle. $\times$ ca.6.9.

Fig. 18. Posterior view of the left side. The maxillary artery was excised at the posterior end of the rete. Since the medial retial branch in this case is underdeveloped, the distribution area of the supero- and the inferomedial retial branches is covered by the superior and inferior twigs of the lateral retial brannch. The meningeal branch arises from the anterosuperior corner of the rete. (※) The posterior end of the maxillary nerve tunnel. ( $\star$ ) The passage for the oculomotor, the trochlear and the abductor nerves and the extraocular muscles. $\times$ ca. 4.9 .

Fig. 19. Lateral view of the left side. Since the anterior retial branch arising from the buccal artery is lacking, the origins of the buccal and the intraretial branches are visible directly. $(\nearrow)$ The origin of the posterior intraretial branch. $(\backslash)$ The destination of the lateral retial branch at the rete. $\times$ ca.6.0.

Fig. 20. Anteroinferior view of the left side. The superior and the inferior intraretial branches form the medial wall of the maxillary nerve tunnel. The lingual branch in this case arises from the component branches of the inferior surface of the rete. (*) The distal end of the tunnel. $\times$ ca. 3.2 . 

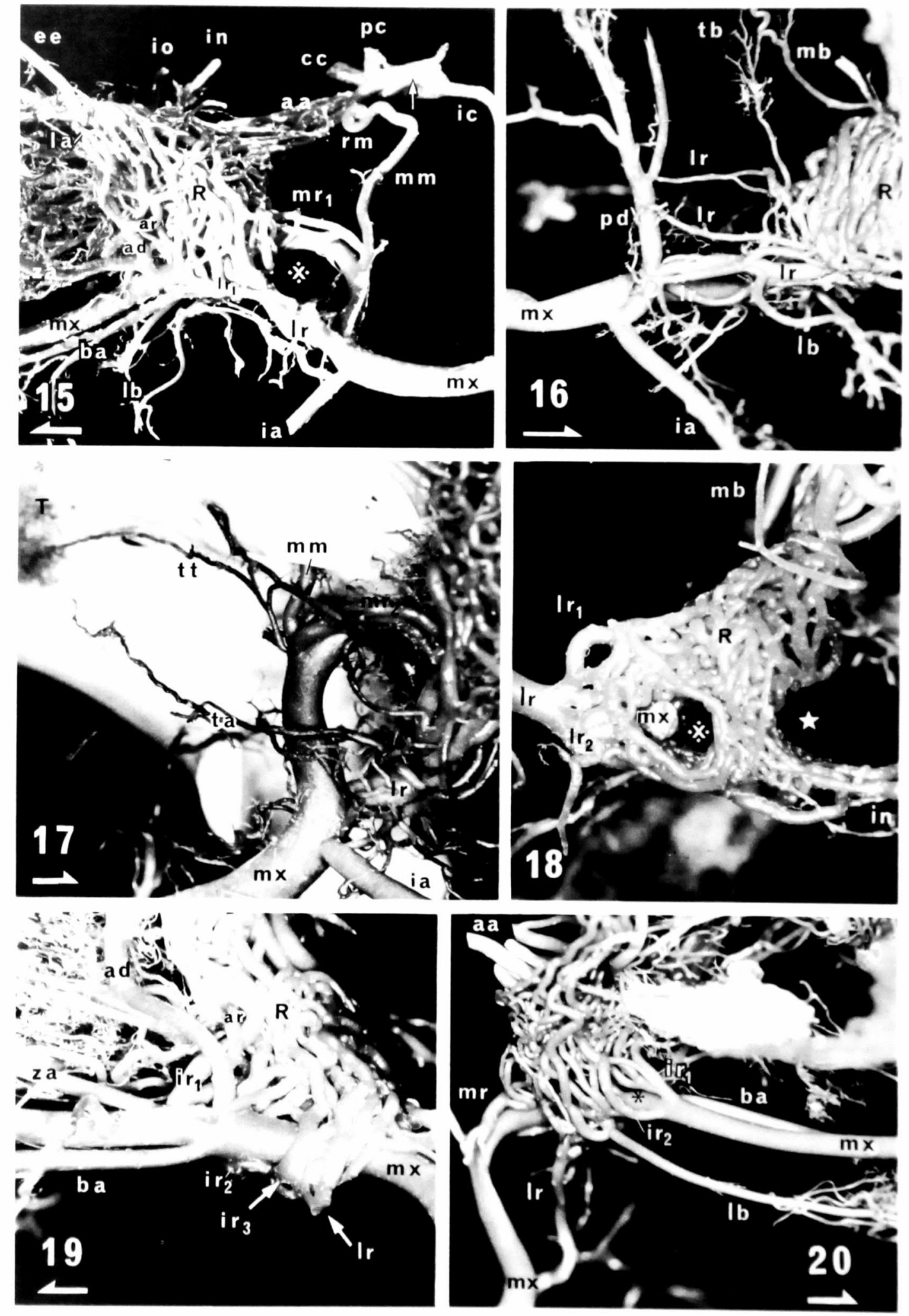


\section{Plate III}

Fig. 21. Medial view of the right side. The medial halves of the component branches of the rete were removed. In this case, four superior intraretial branches and the external ophthalmic artery arise directly from the maxillary artery. The external ophthalmic does not anastomose with the component branches. The external ethmoidal artery and the meningeal branch arise from the anterosuperior corner of the rete (see Fig. 6). × ca.3.8.

Fig. 22. Inferior view of the left side. The component branches of the rete except those of the inferior wall of the maxillary nerve tunnel were removed. The posterior and the inferior intraretial branches form the inferior wall of the tunnel mentioned above. $\times$ ca.4.5.

Fig. 23. Right side. Horizontal section at the level of the middle of the rete. The inferomedial surface of the rete contacts with the orbital cone $(\mathrm{OM}) . \times$ ca. 2.7 .

Fig. 24. Left side. Frontal section through the posterior corner of the rete. Small ganglia $(G)$ are located near the inferior surface of the rete and are supplied with small twigs of the component branches $(r)$ of the rete. $\times$ ca. 55 .

Fig. 25. Inferior view of the left side. Some of the component branches of the inferior surface of the rete turn to the anastomotic artery on its inferomedial surface and the others to the interretial artery and the communicating branch with the external ethmoidal artery at its anteromedial corner. The external ophthalmic artery anastomoses $(\zeta)$ with the internal ophthalmic. $\times$ ca. 2.9 .

Fig. 26. Anterior view of the right side. The external ethmoidal and the extraocular muscular branches diverge from the anterosuperior corner of the rete $(\leftarrow)$, the zygomatic and the anterior deep temporal arteries from the anterolateral corner $(\searrow$, and the interretial artery and the communicating branch with the external ethmoidal artery from the anteromedial corner ( ), respectively. On the anterior surface of the rete, its component branches communicate between the anterosuperior, the anterolateral and the anteromedial corners from the lateral border to the inferior border in the form of a $\mathrm{C}$-shape. (※) The anterior end of the maxillary nerve tunnel. $\times$ ca. 3.2 . 

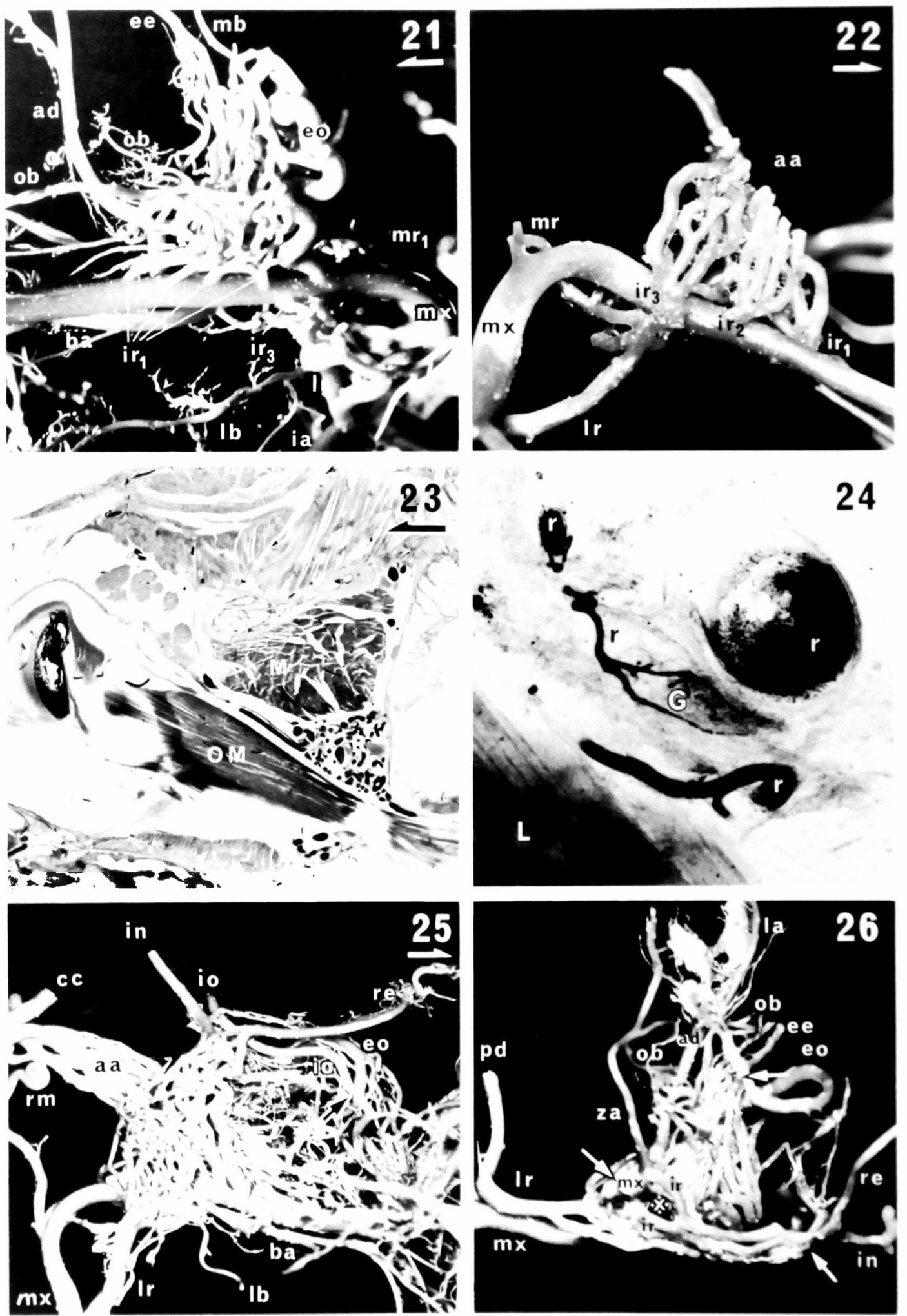

Akimichi Takemura 


\section{Plate IV}

Fig. 27. Superior view of the right side. The anastomotic artery is formed by the posterosuperior and the anteroinferior groups of the component branches of the rete. Both groups flow into one $(\zeta)$ which pours into the remnant of the internal carotid artery to send a great amount of the blood to the cerebral circle. (ac) The anterior cerebral artery. (pc) The posterior communicating artery. $\times$ ca. 4.0 .

Fig. 28. Medial view of the left side. The external ethmoidal artery arising from the anterosuperior corner $(\downarrow)$ of the rete receives a communicating branch from its anteromedial corner $(\vdots) . \times$ ca. 3.0.

Fig. 29. Superior view. The anterior part of the cerebral arterial circle, the anterior and the middle cerebral arteries were removed. Since the left internal ophthalmic artery arising from the circle in this case is considerably thin at its origin $(\downarrow)$, it appears just as it arises from the interretial artery via a communicaing branch $(\ll)$. The right internal ophthalmic arises normally from the circle $(\uparrow)$ (see Figs. 7, 30). (mc) The middle chiasmatic artery. $\times$ ca.4.5.

Fig. 30. Superior view. The anterior parts of the cerebral arteries were removed. The internal ophthalmic arteries, being thick bilaterally, arise from the circle $(\hat{\uparrow})$. A communicating branch between the left internal ophthalmic and the interretial arteries is seen ( $\leftarrow$ ) (see Figs. 7, 29). (H) Hypophysis. (pc) The posterior communicating artery. (mc) The middle chiasmatic artery. $\times$ ca. 3.2 .

Fig. 31. Dog: superolateral view of the left side. The anastomotic artery and ramus are simple in usual cases, but rarely exhibit complex features as shown in this case. Even if the vessels are complicated, they finally flow into the internal carotid after they flow into one. (ac) The anterior cerebral artery. (ma) The middle cerebral artery. (pc) The posterior communicating artery. (see Fig. 15). × ca.3.1. 

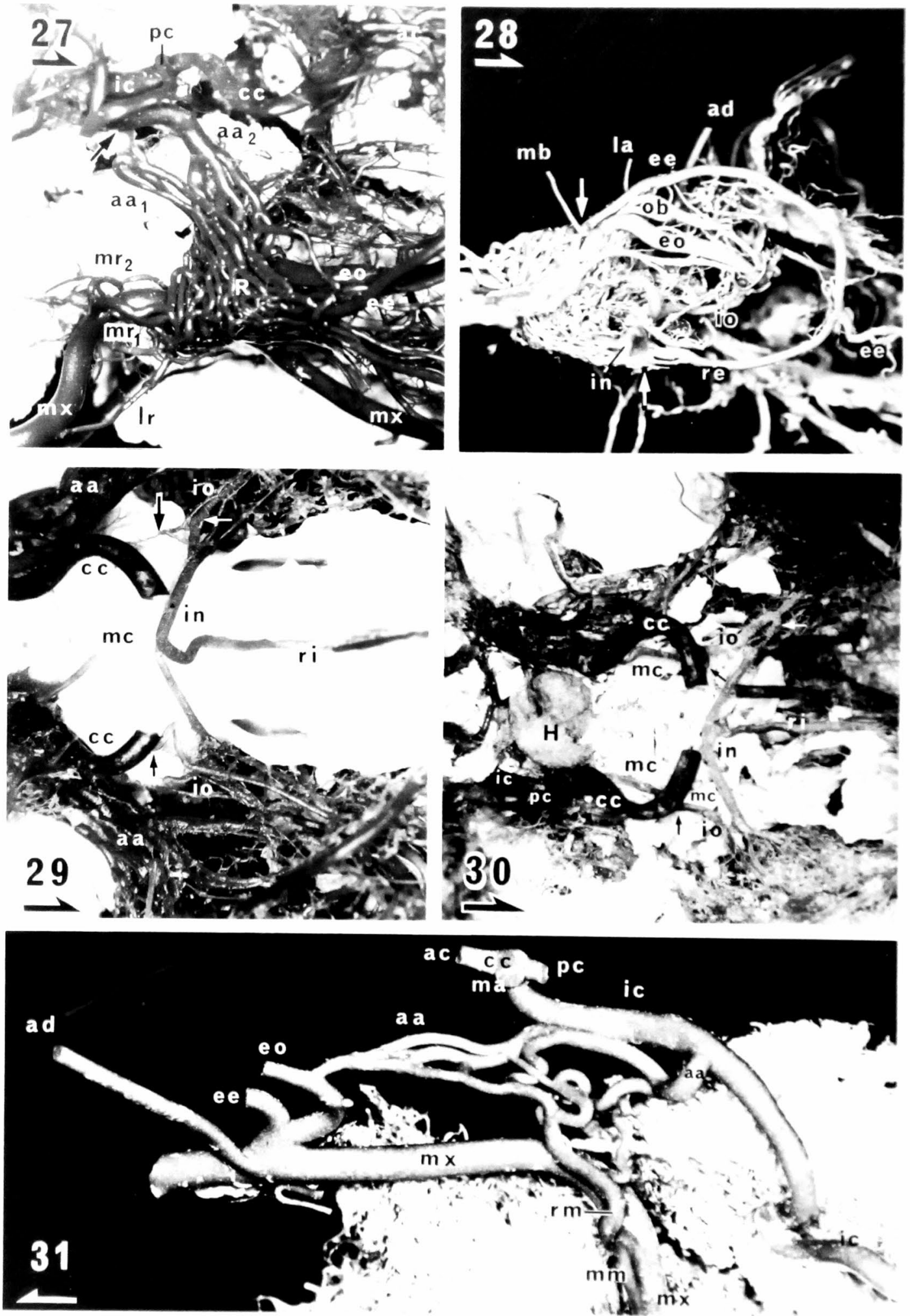